\title{
El Tribunal Constitucional, la cláusula del estado social, los derechos sociales y el derecho a un mínimo vital digno en la República Federal Alemana
}

\author{
Pedro J. Tenorio Sánchez \\ Catedrático (acreditado) de Derecho constitucional \\ Universidad Nacional de Educación a Distancia \\ Letrado del Tribunal Constitucional
}

Recibido: 06.06.2011

Aceptado: 21.11.2011

\begin{abstract}
Resumen: En virtud de la cantidad de sentencias del Tribunal Constitucional en relación con la cláusula del Estado social y los derechos sociales, resulta de gran interés analizar la labor del Tribunal Constitucional al respecto. Es de gran significancia hacer referencia la determinación de los derechos sociales y el derecho a un mínimo vital digno en la República Federal Alemana, en especial a la Sentencia del Tribunal Constitucional Federal alemán, toda vez que, no deja vacío de contenido el imperativo constitucional de la dignidad humana combinado con la cláusula del Estado social, y por otro, deja margen para que sea el Gobierno y el Parlamento los que concreten el derecho.
\end{abstract}

Palabras claves: Tribunal Constitucional, Cláusula de Estado Social, Derechos Sociales.

Abstract: Regarding the number of cases of the Constitutional Court in relation to the social state and social rights, its important to anlyse the work of the Constitutional Court on this matter. It's important to make reference to the determination of social rights and to the vital minimum worth in the Federal Republic of Germany, especially the Case Law of the Federal Constitutional Court, because it does not leave void of content the constitutional imperative of human dignity combined with the Social State clause. On the other hand, it leaves a margin for the Goverment and the Parliament to define this right.

Key words: Constitutional Tribunal, Social State clause, Social Rights.

SUMARIO. 1.- Introducción. 2.- Tribunal Constitucional y cláusula del Estado social. 3.- Tribunal Constitucional y derechos sociales que son derechos fundamentales. 4.- Tribunal Constitucional y valor y eficacia de los principios rectores de la política social y económica. 5.- Addenda: Derecho social fundamental a un mínimo vital digno.

\section{INTRODUCCIÓN}

Una dificultad considerable a la hora de abordar el estudio de la labor de nuestro Tribunal Constitucional en relación con la cláusula del Estado social y los derechos sociales es la amplitud de las fuentes a consultar y en particular el elevado número de sentencias de nuestro Tribunal Constitucional que se han de analizar. 
Para hacernos una idea, consignaremos dos datos. Si buscamos en cuántas sentencias de nuestro Tribunal Constitucional se emplea en los Fundamentos Jurídicos la expresión "Estado social", nos encontramos con que hasta septiembre de 2010 habían sido 158. El otro dato a consignar sería el siguiente: el $15 \%$ de los recursos de amparo que se presentan ante nuestro Tribunal Constitucional invocan un derecho tan relacionado con la cláusula del Estado social como es el de igualdad; una cifra muy considerable, casi igual al porcentaje de recursos que invocan el resto de los derechos fundamentales, excluido el derecho a la tutela judicial efectiva (art. $24 \mathrm{CE}$ ); a lo que debe añadirse que el número total de recursos de amparo interpuesto cada año viene superando en los últimos años los diez mil.

Intentando establecer un orden en nuestro análisis, vamos a distinguir la jurisprudencia de nuestro Tribunal Constitucional en los siguientes ámbitos: en una primera parte vamos a referirnos a la influencia de la cláusula del Estado social, en sí misma considerada (con independencia de los derechos sociales y principios rectores concretos), en la jurisprudencia de nuestro Tribunal; en segundo lugar nos referiremos a la jurisprudencia de nuestro Tribunal en relación con los derechos sociales que de alguna manera pueden ser calificados como derechos fundamentales; tercero, vamos a referirnos a la jurisprudencia de nuestro Tribunal Constitucional relativa a los derechos o principios económicos y sociales, concretamente, la relativa al valor y eficacia de los principios rectores de la política social y económica (Capítulo III del Título I de nuestra Constitución -en adelante CE-)

\section{TRIBUNAL CONSTITUCIONAL Y CLÁUSULA DEL ESTADO SO- CIAL}

La cláusula del art.1.1 CE, incluida la definición del Estado como social, tiene gran relevancia porque contiene, como dice Torres del Moral (Principios, 2010,51) un principio de primer orden que se desarrolla a lo largo del articulado y que impregna todo el texto constitucional y el resto del ordenamiento jurídico, al que hay que interpretar a la luz de dicha declaración. En este sentido, nuestro Tribunal Constitucional viene repitiendo desde la STC 18/1981, de 8 de junio, que "la Constitución incorpora un sistema de valores cuya observancia requiere una interpretación finalista de la norma fundamental". Como ha señalado Aragón (2000, p. 114), se trata de un principio (no regla) orientador de la acción del Estado (no estructural) que indica que la acción pública debe estar orientada a la reducción de la desigualdad social.

Pasando a considerar casos concretos en que nuestro Alto Tribunal ha empleado esta cláusula para extraer conclusiones relevantes cabe mencionar (Pérez Royo, 1984, 170 y ss):

- En la importante STC 11/1981, de 8 de abril, nuestro Tribunal Constitucional señaló (FJ 9) la conexión entre derecho de huelga y Estado social y dedujo de ello consecuencias importantes a la hora de configurar 
el derecho de huelga (art. $28 \mathrm{CE}$ ) en relación con el derecho a tomar medidas de conflicto colectivo por parte de los empresarios (art. $37 \mathrm{CE}$ ). Decimos que es importante porque se trata de la Sentencia en que el Tribunal fijó el concepto de "contenido esencial" de los derechos fundamentales, señaló que los requisitos formales de regulación de los derechos son los del momento en que se aprueba la regulación, consideró en consecuencia constitucional el Decreto-ley regulador del derecho de huelga (a pesar de tratarse de un derecho fundamental regulado en el art. $28 \mathrm{CE}$ que, en consecuencia, ha de ser regulado por ley orgánica: art. $81 \mathrm{CE}$ ), entró a conocer del contenido del Decreto-ley de huelga de 1977 y, con ligeros retoques, lo erigió en régimen jurídico de tal derecho fundamental que había de permanecer vigente hasta la actualidad. Pues bien, en ella se dijo concretamente que no se puede equiparar la huelga, reconocida como derecho fundamental en el art. $28 \mathrm{CE}$, con el cierre patronal, simple derecho cívico reconocido en el art. 37, que no puede ejercerse lícitamente cuando vacía de contenido el derecho constitucional de hacer huelga o se alza como barrera que lo impide; que la Constitución española no recoge el llamado principio de igualdad de armas.

- Nuestro Tribunal Constitucional ha acudido a la cláusula del Estado social para considerar justificadas algunas desigualdades contenidas en el Derecho laboral entre empresarios y trabajadores. Así, para considerar constitucional que la ley establezca que el empresario condenado que quiera recurrir en casación deba depositar la cantidad a la que haya sido condenado (mientras que, al trabajador no se le exige tal requisito): STC $3 / 1983$, de 25 de enero. Y lo mismo con referencia al régimen jurídico del recurso de súplica (STC 14/1983, de 28 de febrero).

- En la STC 19/1982, de 5 de mayo, nuestro Tribunal Constitucional con base en la cláusula del Estado social (art. 1.1 CE), en la cláusula que promueve la igualdad real y efectiva (art. 9.2 CE) y en el principio rector de suficiencia de las pensiones (art. $50 \mathrm{CE}$ ) falló a favor de la compatibilidad de la percepción de una pensión de vejez y otra de viudedad.

Pero más allá de estos casos concretos o de otros que se puedan traer a colación, nuestro Tribunal Constitucional, basándose en la cláusula a la que nos venimos refiriendo, ha jugado un papel precursor en relación con la extensión de los derechos fundamentales a las relaciones entre particulares. La importancia de la cuestión justifica que nos detengamos en ella.

Ni nuestra Constitución ni nuestra Ley Orgánica del Tribunal Constitucional (LOTC en adelante) prevén expresamente la aplicación de los derechos fundamentales en las relaciones entre particulares. Es más, en la LOTC se encuentra un obstáculo explícito a la misma: el art. 44.1.b), que, al regular los requisitos que ha de reunir el recurso de amparo, dice que "las violaciones de los derechos y libertades susceptibles de amparo constitucional, que tuvieran su origen inmediato y directo en un acto u omisión de un órgano judicial podrán dar lugar a...recurso [de amparo] siempre que se cumpla 
[, entre otros, el requisito de] que la violación del derecho o libertad sea imputable de modo inmediato y directo a una acción u omisión del órgano judicial con independencia de los hechos que dieron lugar al proceso en que aquellas se produjeron, acerca de los que en ningún caso entrará a conocer el Tribunal Constitucional" (cursiva nuestra).

Pues bien, el Tribunal Constitucional ha dotado de eficacia a determinados derechos fundamentales en las relaciones entre particulares. La primera sentencia en este sentido fue la STC 38/1981, de 23 de noviembre, relativa a unos trabajadores despedidos por participar en unas elecciones sindicales. Pero la construcción doctrinal que fundamenta tal extensión de la aplicación de los derechos es posterior. El artificio consiste en entender que, cuando un órgano judicial no repara un lesión de un derecho fundamental irrogada por un particular, ha producido, él también, una lesión del derecho fundamental que puede y debe ser reparada mediante el recurso de amparo. Este razonamiento se formula, fuera del ámbito laboral e invocando la cláusula del Estado social (art. 1.1 CE) y la de la igualdad real y efectiva (art. 9.2 CE), en la STC 18/1984 de 7 de febrero. Y en el ámbito laboral, en la STC 177/1988, de 10 de octubre.

Todavía en el ámbito de su papel precursor en la extensión de la aplicación de los derechos fundamentales, ha de anotarse en el haber de nuestro Tribunal Constitucional el hecho de que haya incorporado no sólo esta construcción general, sino también importantes doctrinas concretas, como la de la discriminación directa o indirecta, importada del derecho comunitario (STC 145/1991, de 1 de julio) o la de la acción positiva en pro de la igualdad (STC 128/1987, de 16 de julio).

No podemos concluir este apartado, relativo a la aplicación de la cláusula del Estado social por el Tribunal Constitucional, sin preguntarnos acerca de qué concepción tiene este último respecto del Estado social y en particular con relación a una cuestión trascendental: la irreversibilidad de las conquistas sociales o mantenimiento de las conquistas sociales ya conseguidas.

Pues bien, hasta donde hemos alcanzado a ver, nuestro Tribunal Constitucional no ha aceptado el principio de irreversibilidad de las conquistas sociales sino que, cuando se ha planteado más o menos directamente la cuestión, ha hecho referencia a que los medios económicos son limitados, de donde se desprende una postura más bien contraria. Concretamente, en la STC 97/1990, de 24 de mayo, interpretando el art. $50 \mathrm{CE}$, que hace referencia a que las pensiones han de ser adecuadas, el Tribunal recuerda que el Estado administra medios limitados y además rechaza la idea de inconstitucionalidad por omisión.

\section{TRIBUNAL CONSTITUCIONAL Y DERECHOS SOCIALES QUE SON DERECHOS FUNDAMENTALES}

No es cuestión pacífica la de qué es un derecho fundamental. Esta noción no es pacífica ni siquiera circunscribiéndola a nuestro Derecho constitucional. 
En este último, el tema se plantea muy a menudo en torno a la interpretación del art. $53 \mathrm{CE}$, que regula las diferentes garantías de que gozan las diferentes partes (artículos, secciones o capítulos) en que se agrupan las normas de nuestra Constitución que declaran derechos. Para Jiménez Campo (1999, 17 y ss., especialmente 27) derecho fundamental en nuestro ordenamiento es el que, por contraste con lo dispuesto en el apartado 3 del art. $53 \mathrm{CE}$, deriva del apartado 1 del mismo artículo; es decir, son derechos resistentes, en su "contenido esencial" a la acción legislativa. Por eso, dice el referido autor, merecen la calificación de fundamentales todos los derechos enumerados en el Capítulo II del Titulo I, tanto en la Sección $1^{\mathrm{a}}$ como en la Sección $2^{\mathrm{a}}$.

Sin embargo, este criterio no es el reconocido explícitamente por nuestro Tribunal Constitucional. Como expone el propio autor referido (1999, 20 y ss.) nuestro Alto Tribunal, desde la STC 16/1981, de 18 de mayo, FJ 10, distingue entre derechos fundamentales y derechos constitucionales, estos últimos reconocidos en la Sección $2^{\text {a }}$ del Capítulo II del Título I. Por otra parte, nuestro Tribunal Constitucional limita el calificativo de "fundamentales" a los derechos reconocidos en la Sección $1^{\mathrm{a}}$ del Capítulo II del Título I, esto es, los que requieren para su desarrollo ley orgánica, desde la STC 5/1981, de 13 de febrero. Solo excepcionalmente se ha calificado como derecho fundamental uno de la Sección $2^{\text {a }}$ (STC 46/1983, de 27 de mayo, FJ6, libertad de empresa). En otros casos el Tribunal (STC 56/1982, de 26 de julio, FJ2) ha reservado la calificación derechos fundamentales a los derechos susceptibles de amparo con base en el art. 53.2 CE. De otro lado, nuestro Tribunal considera característica esencial de los derechos fundamentales la aplicabilidad y justiciabilidad inmediatas: SSTC 21/1981, de 15 de junio, FJ 17; 15/1982, de 23 de abril, FJ 8; 16/1982, de 28 de abril, FJ 1; 80/1982, de 20 de diciembre, FJ 1; 39/1983, de 16 de mayo, FJ 3; 31/1994, de 31 de enero, FJ 7.

En suma, y concluyendo esta digresión, en nuestro sistema podemos distinguir entre derechos fundamentales, derechos constitucionales no fundamentales y principios rectores: los primeros serían la igualdad más los de la Sección $1^{\mathrm{a}}$ del Capítulo II del Título I CE, protegidos todos ellos por recurso de amparo ante el Tribunal Constitucional (art. 53.2 CE), y todos menos la igualdad, por reserva de ley orgánica (art. $81 \mathrm{CE}$ ) y reforma reforzada de la Constitución (art. $167 \mathrm{CE}$ ); los segundos, derechos constitucionales no fundamentales, serían los localizados en la Sección $2^{\text {a }}$ del Capítulo II del Título I, protegidos por reserva de ley ordinaria y garantía de su contenido esencial frente a la ley (art. 53.1 CE) y, los terceros, principios rectores de la política social y económica serían los del Capitulo III del Título I CE, sólo aplicables por la jurisdicción ordinaria de acuerdo con lo que dispongan las leyes que los desarrollan (art. 53.3 CE).

En una primera aproximación, se puede decir que la mayoría de los derechos sociales aparecen en ese Capítulo III. Pero llegados a este punto, ha de hacerse la siguiente observación: en principio, hay una tendencial correspondencia en nuestra Constitución entre técnica de protección o garantía de un de- 
recho, naturaleza del mismo, contenido del mismo y tenor literal del precepto que lo reconoce, pero esta cuádruple correspondencia no se produce en todos los casos. Queremos decir con esto que es verdad que las libertades liberales o de autonomía, (que son garantizables mediante un Estado que simplemente cuente con poder legislativo, judicial y ejecutivo garante del orden público, libertades que el sujeto puede ejercer por sí mismo y respecto de las cuales sólo hay que impedir la intromisión), suelen venir garantizadas como derechos públicos subjetivos en su plenitud y como derechos fundamentales. Y es igualmente cierto que la mayoría de los derechos sociales exigen, para alcanzar efectividad, que se organice un servicio público específico, que se dicte regulación de desarrollo, y que se consignen presupuestariamente las cantidades necesarias para pagar el coste de las correspondientes prestaciones, por lo que en principio, se reconocen de una manera más debilitada o condicionada que los derechos fundamentales.

Ahora bien, esto debe ser matizado haciendo dos observaciones. La primera es que no todos los derechos sociales son derechos de prestación, sino que hay derechos sociales de autonomía que puede ejercer el sujeto por sí mismo sin necesidad de que los poderes públicos implanten un servicio público. Pensemos en los derechos de sindicación o de huelga: ambos son derechos de autonomía que, efectivamente, se reconocen como derechos fundamentales en nuestro ordenamiento en el art. 28, que supone la asignación de las máximas garantías que nuestro ordenamiento reconoce a un derecho subjetivo público. Pero es que además el constituyente puede dotar de las máximas garantías a un derecho aunque éste, por su estructura y contenido, sea derecho de prestación. En tal caso, ciertamente habrá construcciones doctrinales o científicas que afirmarán su carácter programático, pero el otorgamiento por la Constitución de garantías máximas acabará obligando a los poderes públicos y en particular al poder judicial a extraer consecuencias de ella. Para concretar: nuestro constituyente decidió insertar un derecho social, el derecho a la educación, en el art. $27 \mathrm{CE}$, dotándolo de esta manera de las máximas garantías; pues bien, creemos que esto no es ajeno al hecho de la expansión efectiva de este derecho entre nosotros y a que sea una realidad la enseñanza básica obligatoria y gratuita como exige el art. 27.4 CE.

Hechas estas observaciones, vamos a referirnos a algunos derechos sociales que son derechos fundamentales.

El primero de ellos es el derecho-principio de igualdad. No vamos a entrar en complejas disquisiciones conceptuales entre igualdad formal y material o entre la igualdad efectiva del art. 9.2 CE y la formal o del art. 14 CE. Aquí nos interesa solamente señalar que, bajo el paraguas de igualdad del art. $14 \mathrm{CE}$ se han cobijado, sea ello técnicamente correcto o no, ideas propias de la igualdad real y efectiva y por ello la jurisprudencia de amparo de nuestro Tribunal Constitucional es susceptible de ser estudiada desde la perspectiva del derecho de igualdad como derecho social. 
Pues bien, este es un derecho en continua revisión, entre otras razones por la tensión entre la igualdad del art. 9.2 CE y la del $14 \mathrm{CE}$. Muy sucintamente cabe resaltar que, en la evolución en pos de la igualdad efectiva, hay una primera fase en la que se aplicó la igualdad real y efectiva del art. 9.2 CE ensayando la igualación entre hombre y mujer "hacia arriba", de modo que se hizo disfrutar al varón de beneficios previstos en la legislación para mujeres, es el caso de las SSTC 81/1982, de 21 de diciembre, (turnos nocturnos); 98/1983, de 15 de noviembre, (turnos nocturnos); 103/1983, de 22 de noviembre, (viudos); y 38/1986, de 7 de noviembre (varones discriminados).

Con posterioridad se detectaron disfunciones o efectos no deseados de la doctrina sentada en los primeros casos y se abrió un proceso de revisión en el que se exploraron nuevos caminos, como la consideración de las ventajas legales reconocidas a la mujer como acciones positivas (STC 128/1987, de 16 de julio, sería el caso inicial cuya doctrina se extiende a otros posteriores STC 109/1993, de 25 de marzo-) o el reconocimiento de un mayor margen a los titulares del poder normativo (STC 5/1992, de 16 de enero).

Finalmente, se revisa abiertamente la posibilidad de las pretensiones de igualación "por arriba", tanto en el ámbito laboral como en el de la Seguridad Social. En el ámbito laboral la STC 28/1992, de 9 de marzo, recoge los elementos esenciales del cambio de criterio. En el ámbito de la Seguridad Social, es importante en este sentido la STC 315/1994, de 28 de septiembre, sobre diferencias de trato en un montepío de una diputación comercial. Igualmente destacable es la STC 16/1995, de 24 de enero, acerca de la jubilación temprana beneficiosa para la mujer no aplicada por ser considerada discriminatoria.

Otro derecho social fundamental en el que vamos a detenernos es el derecho a la sindicación. Son muchas las sentencias relativas a la libertad de sindicación a las que habría que referirse. Quizá la sentencia capital en la materia sea la STC 11/1985, de 30 de enero, sobre la Ley Orgánica de Libertad Sindical. Pero lo que nos interesa, más que intentar referirnos a muchos aspectos de este derecho, es señalar que la incidencia de la jurisprudencia del Tribunal en la construcción del mismo ha sido amplia y profunda, hasta tal punto que ha llevado a cabo una ampliación de su contenido constitucional discutible.

Está fuera de discusión que el contenido esencial de este derecho se ha de proteger. Tal contenido, integrado por la autonomía organizativa, la libertad programática, el derecho a participar en la negociación colectiva y en las medidas de conflicto colectivo, ha de ser plenamente reconocido. Pero nuestro Tribunal Constitucional no se ha dedicado a proteger estos contenidos, sino además, otros adicionales. Lo ha hecho, en una primera fase, incluyendo dentro del contenido esencial otros contenidos atípicos del derecho a la sindicación. Pero es que además a partir de la STC 40/1985, de 13 de marzo, sobre el crédito horario, el Tribunal declara que hay que distinguir entre el contenido esencial del derecho a la sindicación, que es el que se protege con motivo del recurso de inconstitucionalidad, y el contenido constitucional del derecho, 
que no comprende solamente el esencial, sino otra serie de facultades que llama "contenido adicional". Este admite las más variadas facultades. Un ejemplo de esto lo ofrece la STC 281/2005, de 7 de noviembre, en la que el Tribunal consideró que el servidor informático de una empresa debe estar a disposición de los representantes sindicales para enviar los mensajes del sindicato. De este modo, el derecho de sindicación se convierte en un derecho de prestación.

A lo que debe añadirse que nuestro Tribunal Constitucional, en materia de sindicación, ha desbordado los límites legales del amparo y ha convertido a este en una especie de recurso de casación (de modo similar a lo que ocurre en el ámbito del derecho de huelga y, fuera del ámbito laboral, en el derecho a la libertad de expresión y a la información) frente al art. 54 LOTC, según el cual "cuando la sala o, en su caso, la sección conozca del recurso de amparo respecto de las decisiones de jueces y tribunales limitará su función a concretar si se han violado derechos o libertades del demandante y a preservar o restablecer estos derechos o libertades, y se abstendrá de cualquier otra consideración sobre la actuación de los órganos jurisdiccionales".

La profundidad y amplitud con la que el Tribunal Constitucional revisa el criterio del Tribunal Supremo es patente leyendo la STC 281/2005, de 7 de noviembre. El caso enfrentó al BBVA con el sindicato Federación de Servicios Financieros y Administrativos de Comisiones Obreras (Comfia-CCOO). El primero, que venía permitiendo un uso limitado del correo electrónico por el sindicato, a partir de un determinado momento y ante la avalancha de mensajes enviados por el mismo, decidió disponer el servidor para que rechazara los mensajes de la dirección electrónica del sindicato. Planteada demanda de conflicto colectivo por esto último, la Sala de lo Social de la Audiencia Nacional la estimó parcialmente, declarando que el demandante podía enviar correos electrónicos con la mesura y normalidad inocuos con la que lo había hecho antes de la avalancha de correos que motivó el bloqueo dispuesto por la empresa. Interpuesto recurso de casación por el banco, el Tribunal Supremo lo estimó: mientras no se consintiera por la demandada expresamente, no hay norma alguna que conceda al sindicato derecho a usar el sistema informático de la empresa.

Pues bien, nuestro Tribunal Constitucional, tras repasar su doctrina acerca del contenido esencial y adicional del derecho de sindicación y sobre la distinción de contenido adicional de fuente legal y de fuente convencional y señalar que los sindicatos no pueden demandar actos positivos de naturaleza promocional si no existe una fuente generadora de tal obligación, afirma que no puede confundirse la ausencia de una obligación provisional que grave al empresario con la posibilidad de que este adopte decisiones de carácter meramente negativo, disuasorias o impeditivas del desarrollo del derecho dirigidas únicamente a entorpecer su efectividad. Esto sentado, el Tribunal Constitucional afirma que el derecho a usar el correo electrónico o medios preexistentes en la empresa para la comunicación sindical está amparado por 
el art. 28.1 CE, si se ejerce dentro de ciertos límites, concretamente: a) la comunicación no podrá perturbar la actividad normal de la empresa; b) no podrá perjudicarse el uso especifico empresarial preordenado para el medio en cuestión; c) no podrá ocasionar gravámenes adicionales para el empleador, en particular, mayores costes. En consecuencia, se declara vulnerado el derecho a la libertad sindical y se anula la sentencia del Tribunal Supremo.

La Sentencia, por tanto, amplía el contenido del derecho a la libertad sindical, que se convierte en derecho de prestación, y lleva a cabo una ponderación de los intereses de las partes que sustituye la que había hecho el Tribunal Supremo.

Para terminar esta incompleta exposición de los derechos sociales que son derechos fundamentales, hagamos un apunte sobre el derecho al medio ambiente, reconocido en el art. 45 CE. La STC 199/1996, de 3 de diciembre, había negado el carácter de derecho fundamental de este derecho, pero con posterioridad la STC 119/2001, de 24 de mayo, abre una vía para su reconocimiento. En relación con este tema hay que traer a colación la relativa discrepancia entre el TEDH y nuestro Tribunal Constitucional.

En efecto, el TEDH ha conectado el derecho al medioambiente con el derecho a la vida privada y familiar para dispensar a aquél la protección que de otro modo no podía, argumentando que el derecho a la vida privada y familiar de los habitantes de una casa había sido vulnerado por la emisión de ruidos y humos de una cercana estación depuradora de aguas y residuos: STEDH de 9 de diciembre de 1994, caso López Ostra c. España, con un precedente en la STEDH de 17 de octubre de 1986, caso Powell y Rainer c. Reino Unido. Nuestro Tribunal Constitucional, sin embargo, ha negado que esa conexión haga del derecho al medioambiente un derecho fundamental, habida cuenta del tratamiento constitucional del mismo: STC 199/1996, de 3 de diciembre.

No obstante, con posterioridad, nuestro Tribunal Constitucional se ha movido en la vía abierta por el TEDH, utilizando la vía argumental de este último para impedir que ciertas contaminaciones, como la acústica, vulneren el derecho a la integridad física y psíquica (art. $15 \mathrm{CE}$ ) y la intimidad personal y familiar, sobre todo, cuando esa contaminación alcanza niveles en los que se convierte en objetivamente evitable e insoportable: STC 119/2001, de 24 de mayo. Existen además dos Sentencias de 2004 (SSTC 16/2004, de 23 de febrero, y 25/2005, de 26 de febrero; Tenorio, 2005, 25 y ss.) de diferentes Salas del Tribunal, que resuelven en esta materia asuntos similares en sentido contradictorio.

\section{TRIBUNAL CONSTITUCIONAL Y VALOR Y EFICACIA DE LOS PRINCIPIOS RECTORES DE LA POLÍTICA SOCIAL Y ECONÓ- MICA}

En cuanto a los principios rectores de la política social y económica, contenidos entre los arts. 39 y $52 \mathrm{CE}$, lo primero que debe señalarse es que por 
razón de su ubicación en la Constitución, en virtud del art. 53.3 CE, son los derechos, intereses o posiciones jurídicas subjetivas más débilmente protegidos por nuestra Constitución.

El alcance de estos derechos viene regulado por la propia Constitución, en el art. 53.3, precepto con dos incisos, el primero de los cuales dice que "el reconocimiento, el respeto y la protección de los principios reconocidos en el Capítulo Tercero informarán la legislación positiva, la práctica judicial y la actuación de los poderes públicos". Por su parte el segundo inciso dice que "sólo podrán ser alegados ante la jurisdicción ordinaria de acuerdo con lo que dispongan las leyes que los desarrollen".

\subsection{Pues bien, el art.53.3 no resuelve todas las cuestiones que plantea el valor o alcance jurídico de los principios rectores, pero sí establece al- gunas reglas de interpretación y aplicación de tales principios dig- nos de ser tenidos en consideración.}

1) Del art. 53.3 (Jiménez Campo, 1996, 439 y ss.) se deriva que en el Capítulo Tercero del Título I no hay derechos subjetivos en sentido estricto; no hay derechos que merezcan la calificación de fundamentales, denominación que la Constitución reserva a lo proclamado en otros preceptos: en los arts. 15 a 29 de la Constitución titulados "de los derechos fundamentales y de las libertades públicas". La negativa de nuestro Tribunal Constitucional a considerarlos derechos fundamentales es clara. En la STC 36/1991, de 29 de enero, FJ 5, con motivo de la delimitación del alcance del art. 39.4 CE, se dijo que "en general (art. 53.3 CE) los principios reconocidos en el Capítulo III del Título I, aunque deben orientar la acción de los poderes públicos, no generan por sí mismos derechos judicialmente actuables". En la STC 14/1992, de 10 de febrero, FJ 11, se dijo, respecto del art. 51.1 CE, relativo a la protección de los consumidores y usuarios, lo siguiente:

"Este precepto enuncia un principio rector de la política social y económica, y no un derecho fundamental. Pero de ahí no se sigue que el legislador pueda contrariar el mandato de defender a los consumidores y usuarios, ni que este Tribunal no pueda contrastar las normas legales, o su interpretación y aplicación, con tales principios. Los cuales, al margen de su mayor o menor generalidad de contenido, enuncian proposiciones vinculantes en términos que se desprenden inequívocamente de los arts. 9 y 53 CE (STC 19/1982, de 5 de mayo, FJ 6). Ahora bien, es también claro que, de conformidad con el valor superior del pluralismo político (art. 1.1 CE), el margen que estos principios constitucionales dejan al legislador es muy amplio. Así ocurre con el art. 51.1 CE, que determina unos fines y unas acciones de gran latitud, que pueden ser realizados con fórmulas de distinto contenido y alcance. Pero, en cualquier caso, son normas que deben informar la legislación positiva y la práctica judicial (art. 53. $3 \mathrm{CE}$ )". 
En fin, en la STC 199/1996, de 3 de diciembre, FJ 3, se dijo que "no puede ignorarse que el art. 45 de la Constitución enuncia un principio rector, no un derecho fundamental. Los Tribunales deben velar por el respeto al medio ambiente, sin duda, pero de acuerdo con lo que dispongan las leyes que desarrollen el precepto constitucional" y se remitía la Sentencia a su vez a otras sentencias del propio Tribunal Constitucional.

2) Los principios rectores constituyen normas vinculantes. Esto se desprende del propio tenor literal del art. 53.3 CE, que impone al legislador y a los órganos aplicadores del derecho el reconocimiento, el respeto y la protección de dichos principios. Más concretamente, el Tribunal Constitucional ha utilizado estas normas como canon de la validez de la ley en dos ocasiones al menos. Se trata del principio de protección de la familia, art. 39.1, que fue utilizado para basar un juicio contrario a la constitucionalidad en la STC 45/1989, de 20 de febrero, sobre el IRPF y en la STC 222/1992, de 11 de diciembre, sobre la extensión del beneficio de la subrogación en el arrendamiento al miembro supérstite de una unión de hecho. Sin embargo, en ambos casos la motivación del fallo se redactó sobre todo a partir del art. $14 \mathrm{CE}$, cumpliendo la invocación del art. 39.1 CE una función complementaria. Es más, en la STC 45/1989, de 20 de febrero, se realizó una afirmación que relativizaba la fuerza obligatoria de estos principios rectores al señalar que es improbable que una norma legal cualquiera pueda ser considerada inconstitucional por omisión. Concretamente, dijo: "hay que reconocer, en primer término, que la naturaleza de los principios rectores de la política social y económica que recoge el Capítulo III del Título I de nuestra Constitución hace improbable que una norma legal cualquiera pueda ser considerada inconstitucional por omisión, esto es, por no atender, aisladamente considerada, el mandato a los poderes públicos y en especial al legislador, en el que cada uno de-esos principios por lo general se concreta. No cabe excluir que la relación entre alguno de esos principios y los derechos fundamentales (señaladamente el de igualdad) haga posible un examen de este género (cf., por ejemplo, nuestra STC 155/1987), ni, sobre todo, que el principio rector sea utilizado como criterio para resolver sobre la constitucionalidad de una acción positiva del legislador, cuando ésta se plasma en una norma de notable incidencia sobre la entidad constitucionalmente protegida" (STC 45/1989, de 20 de febrero, FJ 4). Según Fernández-Miranda (2003, p. 160), de este fragmento se la STC 45/1989, se desprende: $1^{\circ}$. Que se descarta toda posibilidad de la omisión legislativa plena; $2^{\circ}$. Que se considera improbable el control de la omisión parcial o norma legal incompleta; $3^{\circ}$. Que dentro de esta improbabilidad, sólo hay posibilidades cuando exista una directa vinculación entre el principio rector y algún derecho fundamental, singularmente, el derecho a la igualdad.

3) El primer inciso del art. 53.3 CE nos indica que el destinatario primero de las normas contenidas en el Capítulo III es el legislador, todos los legisladores de nuestro Estado. Ahora bien, se dice que informarán la práctica judicial y la jurisprudencia de nuestro Tribunal Constitucional ha declarado, por 
ejemplo en la STC 19/1982, de 5 de mayo, FJ 6, que el art. 53.3 impide considerar a los principios del Capítulo III "como normas sin contenido y que obliga a tenerlos presentes en la interpretación tanto de las restantes normas constitucionales como de las leyes". A nuestro juicio, del precepto, y de la posición institucional de las Administraciones Públicas (y del propio art. 103.1 $\mathrm{CE}$ ), se deduce que estas pueden actuar directamente, sin mediación legal, a partir de los principios rectores, salvo en los casos en que las normas del Capítulo III incorporan reservas de Ley.

Por lo demás es doctrina constitucional muy reiterada que en el Capítulo III de la Constitución no se pueden hallar fundamentos para la atribución de competencias a las instituciones generales del Estado frente a las Comunidades Autónomas (SSTC 64/1982, de 4 de noviembre, FJ 2; 35/1983, de 11 de mayo, FJ 3; 152/1988, de 20 de julio, FJ 2, y 59/1995, de 17 de marzo, FJ 3)

Esta obligación de tener en cuenta los principios rectores, este carácter vinculante de los misos; se puede concretar en los siguientes puntos:

En primer lugar, postulan determinadas políticas legislativas y elevan la protección de determinados bienes jurídicos a la categoría de fin del Estado, a conseguir en cumplimiento de la Constitución. Afinando más, conviene precisar que los principios rectores tienen naturaleza programática, en el sentido de que señalan o imponen objetivos al poder público, y en particular al legislador, pero en tales términos que la ley no puede ser juzgada con arreglo a su grado de consecución de los mismos. En este sentido, hay que distinguir (Jiménez Campo, 1999, p. 129) entre objetivos y fines, ya que estos últimos sí imponen exigencias que permiten el control de las normas. Sería el caso, por ejemplo, de los fines prohibidos por el art. 14, o del fin del mantenimiento del orden público que puede justificar la limitación de las libertades del art. 16 CE.

En segundo lugar, posibilitan el control constitucional de las leyes de desarrollo, tanto desde el Tribunal Constitucional como desde los Tribunales ordinarios (a través de la cuestión de inconstitucionalidad). Ya hemos visto que el Tribunal Constitucional ha considerado los principios rectores como posible canon o medida de validez de la ley.

En tercer lugar, este mandato de actuación favorable implica la prohibición de cualquier actuación estatal que perjudique a estos principios, eficacia esta de la que podemos encontrar supuestos en nuestra jurisprudencia constitucional. En este sentido, la STC 19/1982, de 5 de mayo, declaró que el art. $50 \mathrm{CE}$ (protección de la tercera edad) "manda que se deseche la aplicación de una regla que conduce a un resultado opuesto al que dicho precepto constitucional declara deseable" (FJ 6) y en consecuencia se pronunció en contra de una interpretación de la Administración y de un órgano judicial que habían considerado incompatibles la pensión de viudedad y la de jubilación. Por su parte, la STC 45/1989, de 20 de febrero, FJ 4 en particular, declaró inconstitucionales determinados preceptos tributarios que podían suponer mayor carga impositiva como consecuencia de estar casado, entre otros motivos, por ser in- 
compatibles con el mandato constitucional de protección de la familia y el matrimonio.

En cuarto lugar, otra función que cumplen estos principios rectores es la de justificar limitaciones de derechos fundamentales o de otros bienes constitucionales. Nuestro Tribunal Constitucional considera que el contenido de los derechos fundamentales sólo puede limitarse en virtud de una ponderación con otros bienes, derechos o principios que cuenten con reconocimiento constitucional. En este sentido, cabe recordar las SSTC 120/1990, de 27 de junio, FJ 8; 57/1994, de 28 de febrero, FJ6. Así por ejemplo, el reconocimiento constitucional de la protección del medio ambiente (art. $45 \mathrm{CE}$ ) o del patrimonio histórico-artístico (art. $43 \mathrm{CE}$ ) justifica el establecimiento de limitaciones al derecho de propiedad (art. $33 \mathrm{CE}$ ) sobre bienes inmuebles: así lo dicen expresamente las SSTC 227/1988, de 29 de noviembre, acerca de la ley de aguas, FJ 7 y la 66/1991, de 22 de marzo, FJ 3. Sin ánimo de agotar los ejemplos, cabe añadir que la protección de la familia (art. 39.1 CE) puede justificar un límite a la propiedad como el de reconocer a terceros (miembros de la familia) el derecho a subrogarse en la posición del arrendatario, como señaló la STC 222/1992, de 11 de noviembre, FJ 4 A.

En quinto lugar, dentro del ámbito últimamente mencionado, es decir, de la virtualidad justificadora de limitaciones de derechos fundamentales o de otros bienes constitucionales, ha de destacarse la existencia de varios preceptos entre los arts. 39 a 52 CE que identifican a grupos de personas necesitados de especial protección: hijos menores y madres (art. 39 CE), trabajadores españoles en el extranjero (art. $42 \mathrm{CE}$ ), jóvenes (art. $48 \mathrm{CE}$ ), minusválidos (art. $49 \mathrm{CE}$ ), ancianos (art. $50 \mathrm{CE}$ ) y consumidores y usuarios (art. $51 \mathrm{CE}$ ). Pues bien, el Tribunal ha hecho uso de estos principios rectores en el sentido expuesto como resume la STC 190/2005, de 7 de julio, FJ 4, que senala los siguientes ejemplos: la maternidad y, por tanto, el embarazo y el parto son una realidad biológica diferencial objeto de protección, derivada directamente del art. 39.2 CE y, por tanto, las ventajas o excepciones que determine para la mujer no pueden considerarse discriminatorias para el hombre (STC 109/1993, de 25 de marzo, FJ 4, sobre la licencia para la lactancia en el trabajo); no se debe considerar contrario al art. $14 \mathrm{CE}$ (principio de igualdad), ni al art 23.2 CE (derecho de acceder en condiciones de igualdad a las funciones y cargos públicos), una reserva porcentual de plazas para minusválidos en una oferta de empleo público en atención al mandato de protección de los discapacitados que contiene el art. 49 CE (STC 269/1994, de 3 de octubre, FJ 4).

Sexto. Se trata de normas programáticas, que efectivamente tienen el mero valor informador a que hace referencia el art. 53.3 CE, en sentido similar también a lo dispuesto en el Título Preliminar del Código Civil. En general, los preceptos del capítulo tercero del título I CE son mandatos vinculantes de actuación que vinculan a los poderes públicos de manera objetiva, imponen tareas estatales de desarrollo permanente y contienen prohibición de cualquier actuación estatal contraria a los mismos. 
Séptimo. En fin, legitiman las exacciones patrimoniales coactivas de carácter específico que los poderes públicos impongan a los particulares, así como el sostenimiento de los servicios necesarios con cargo a los ingresos públicos generales.

\subsection{Del tenor literal, contenido y naturaleza de los principios rectores, se desprende que muchos de ellos tienen un alcance que va más allá de lo que podría desprenderse del art. 53.3 CE.}

En este sentido, cabe señalar:

a) Muchos preceptos contenidos entre los arts. 39 a 52 CE son además mandatos constitucionales de optimización, entendiendo por ello principios que imponen que el valor que expresan se realice en cada momento en la medida de lo jurídica y fácticamente posible. Esta idea se encuentra en la jurisprudencia constitucional. Así, con apoyo en los arts. 41 y $50 \mathrm{CE}$, la STC 189/1987, de 24 de noviembre, FJ 10, dijo que tales preceptos imponen un deber de configurar el sistema de seguridad social más adecuado para conseguir los fines constitucionalmente previstos dentro de las posibilidades reales. Ya hemos visto que, en relación con estos mandatos de optimización no existe ningún reconocimiento constitucional de lo que algunos han llamado la "irreversibilidad de las conquistas sociales". Parece que para el Tribunal Constitucional solo las conquistas sociales fijadas en la propia Constitución (por ejemplo, la limitación de la jornada laboral o las vacaciones periódicas retribuidas: art. 40.2) serían indisponibles para el legislador. Éste, en todo lo demás no queda sujeto a su propia obra (SSTC 134/1987, de 21 de julio, FJ 5; 97/1990, de 24 de mayo, FJ 4 y 222/1992, de 11 de diciembre, FJ 6)

Además, siguiendo a Jiménez Campo (1999, pp. 131-132), son preceptos que tienen un alcance que excede del marco del art. 53.3 CE, los que a continuación se incluyen en los apartados b), c), d) y d).

b) Mandatos simples de regulación al legislador que no imponen tareas permanentes al Estado, como por ejemplo: obligación de permitir legalmente la investigación de la paternidad (art. 39.2 CE); regulación de las horas de jornada laboral y de las vacaciones periódicas retribuidas (art. 40.2 CE); regulación de sanciones penales y administrativas, y de obligación de declarar el daño causado en materia de medio ambiente (art. 45.3 CE); regulación de sanciones penales para aquellos que atenten contra el patrimonio histórico-artístico (art. $46 \mathrm{CE}$ ); regulación de la forma en que la comunidad participará en las plusvalías que genere la acción urbanística de los entes públicos (art. 47.2 CE); regulación de las organizaciones profesionales que contribuyan a la defensa de los intereses económicos que le sean propios (art. 52 CE y además véase STC 179/1994, de 16 de junio, FJ 5).

c) Preceptos que contienen simples reservas de ley, esto es que identifican de forma general un ámbito material más amplio que el de una norma específica que debe ser regulado por la ley (véase la STC 227/1993, de 9 de julio, FJ 4). 
d) Normas de igualdad, por ejemplo, la reiteración de lo ya establecido con carácter general respecto de los hijos en el artículo 14, en el artículo 39.2: igualdad de los hijos con independencia de su filiación. Otras imponen, más que permiten, un trato singularizado a favor de determinadas categorías o grupos y en consecuencia deben considerarse concreciones del art. 9.2: protección de las madres (art. 39.2 CE), de la infancia (art. 39.4 CE), de los minusválidos (art. $49 \mathrm{CE}$ ) o de los ancianos (art. 50). Este tipo de normas, para nuestro Tribunal Constitucional puede dar fundamente a reglas diferenciadoras (SSTC 128/1987, de 16 de julio, FJ 10; 173/1993, de 27 de mayo, FJ 3; 55/1994, de 24 de febrero, FJ 2, y 269/1994, de 3 de octubre, FJ 4).

e) Garantías institucionales

i) Nuestro Tribunal Constitucional, con base en el art. $41 \mathrm{CE}$, ha sostenido que la seguridad social es objeto de garantía institucional en nuestra Constitución. Concretamente la STC 37/1994, de 10 de febrero, FJ 3D, dijo que el art. $41 \mathrm{CE}$ "consagra en forma de garantía institucional un régimen público cuya preservación se juzga imprescindible para asegurar los principios constitucionales, estableciendo un núcleo o reducto indisponible para el legislador, de tal suerte que ha de ser preservado en términos recognoscibles para la imagen que de la misma tiene la conciencia social en cada tiempo y lugar".

El art. 41 CE, según nuestro Tribunal Constitucional, establece un sistema de prestaciones que no puede estar basado exclusivamente en el equilibrio cuota-prestación, y en el que las cuotas de los afiliados, así como las prestaciones a dispensar, sus niveles y condiciones, no pueden venir determinadas por un régimen contractual, de acuerdo de voluntades, sino por reglas legales que se integran en el ordenamiento jurídico (SSTC 65/1987, de 21 de mayo, y 37/1994, de 10 de febrero).

No obstante, nuestro Tribunal Constitucional no siempre ha sido estrictamente coherente con este planteamiento. Así, como indica A. Torres del Moral (2010, p. 620-621), en las pensiones de viudedad ha interpretado la situación de necesidad de la que habla el art. 41 como mera producción de un daño (la muerte de un cónyuge): entre otras, SSTC 142/1990, de 20 de septiembre, y 184/1990, de 15 de noviembre.

ii) Probablemente se puede también considerar garantizada institucionalmente la institución de la familia en el art. 39.1 CE (al parecer, así lo considera la STC 222/1992).

$\mathrm{El}$ art. $39 \mathrm{CE}$ establece el principio de protección de la familia tratando los aspectos que han venido considerándose fundamentales de la misma. Algunos autores, en particular Torres del Moral, señalan que hay una superación de la realidad social del modelo que tuvieron los constituyentes (2010, p. 624 y ss.). A este respecto sin embargo, hemos de tener en cuenta que nuestro Tribunal Constitucional, STC 47/1993, de 8 de febrero, no considera homologables todos los modelos familiares posibles.

Además, nuestro Tribunal Constitucional ve cierta afinidad entre los conceptos de matrimonio y familia, ya en el régimen tributario, ya en las prerro- 
gativas de funcionarios consortes habituales en la Administración (sobre el tratamiento fiscal de la familia, v. SSTC 209/1988, de 10 de noviembre, y 45/1989, de 20 de febrero; sobre funcionarios consortes, v. STC 192/1991, de 14 de octubre). La familia basada en el matrimonio y la que no se basa en el mismo no deben recibir necesariamente el mismo tratamiento legal, pero no son compatibles con el art. $39 \mathrm{CE}$ las normas que privan injustificadamente de protección a las segundas (STC 222/1992, de 11 de diciembre).

No está claro que pueda ser la protección jurídica de la familia como algo distinto de la protección social y económica. A. Torres del Moral trae a colación a este respecto la jurisprudencia del TEDH que, en consideración de la familia, considera injustificada la expulsión de un extranjero del territorio nacional, aunque pesen sobre él reiteradas condenas, si su familia reside con él: SSTEDH de 18 de febrero de 1991, caso Moustaquim, y de 26 de marzo de 1992, caso Beldjoudi.

iii) En cambio, nuestro Tribunal ha excluido el concepto y la técnica de la garantía institucional para las organizaciones profesionales a las que se refiere el art. 52 CE (STC 179/1994, de 16 de junio, FJ 5).

\section{ADDENDA: DERECHO SOCIAL FUNDAMENTAL A UN MÍNIMO VITAL DIGNO.}

\subsection{Introducción}

Aun siendo entusiasta defensor de los derechos sociales, en varias ocasiones he explicado que el Tribunal Constitucional no considera irreversibles las conquistas sociales y no considera derechos fundamentales la mayoría de los derechos sociales de prestación. Añado que no podía ser de otra manera, ya que, si todos los principios rectores de política social y económica del Capítulo III fueran derechos subjetivos públicos en sentido estricto, de tal manera que cualquier persona pudiera solicitar una sentencia favorable en base a los preceptos de la Constitución, sin mediar desarrollo legislativo y normativo, ni consignaciones presupuestarias, entonces comenzaría a dictarse un conjunto abigarrado y caótico de sentencias reconociendo el derecho a las prestaciones más diversas. Imaginemos, por ejemplo, que cualquier persona, con la sola invocación del precepto constitucional, pudiera obtener una sentencia que condenara al Estado a proporcionarle una vivienda o cualquiera de los otros derechos reconocidos en el Capítulo III. En este caso, en los años sucesivos, los Presupuestos Generales de los entes públicos, tendrían que limitarse a dar ejecución al conjunto abigarrado de sentencias que se hubieran dictado en años anteriores, que dependería de las iniciativas de los ciudadanos para pleitear, de la habilidad de los abogados y del criterio de los jueces. Es decir, no tendría el Gobierno la iniciativa para proponer un presupuesto en función de las prioridades políticas que considerara oportunas y con las que hubiera ganado las correspondientes elecciones. Quiero decir con ello, que puesto que los recursos económicos son limitados, la negación de la condición 
de derechos subjetivos a los derechos sociales, es consecuencia, o es coherente, entre otras cosas, con la división de poderes. Es al Gobierno y al Parlamento a los que corresponde decidir las prioridades del gasto público.

Naturalmente, con ello no estaba afirmando que las sentencias de los tribunales no tuvieran que ser cumplidas por los Presupuestos Generales del Estado, sino todo lo contrario.

Sin embargo, mi postura no es comprendida por los que se consideran auténticos "partidarios de los derechos sociales", que reaccionan afirmando que hay medios económicos suficientes para satisfacer los derechos sociales, y que si no se satisfacen es tan sólo por falta de voluntad política. Y también se me dice que yo mismo había reconocido que el derecho a la educación en nuestro sistema es un derecho fundamental a pesar de su naturaleza de prestación social.

Sigo pensando que, en términos generales, los derechos de prestación no pueden ser protegidos por los jueces sin mediación del legislador. No puede quedar al arbitrio de los jueces en qué supuestos, por ejemplo, la Administración tiene que construir una vivienda a una persona.

Si una Constitución protege, con las mismas garantías que los derechos de autonomía, los derechos de prestación, generaría una situación caótica en la que probablemente acabarían desprestigiándose las resoluciones judiciales, los derechos y la Constitución. Ciertamente, el constituyente, en países con una economía suficientemente fuerte, puede privilegiar algún derecho social de prestación y otorgarle protección directa ante los tribunales. Es lo que ha ocurrido entre nosotros, con el derecho a la educación. Pero si se intentara hacer igual con todos los derechos de prestación se pasaría a una situación caótica.

Por reconocer que los recursos económicos son escasos, no se es enemigo de los derechos sociales. Lo que se quiere decir cuando se dice que no son derechos fundamentales o derechos subjetivos públicos exigibles ante los tribunales sin mediación del legislador, no es que no existan, sino que, dado el carácter excesivamente genérico de las cláusulas constitucionales y la escasez de los recursos económicos, lo racional y democrático es que el legislador concrete qué prestaciones sociales son prioritarias, y las configure dándoles contenido concreto. No es que los derechos sociales no sean en absoluto derechos subjetivos, sino que no lo son en su plenitud sin la mediación de un legislador que los concrete.

Desde esta perspectiva, creo de gran interés la Sentencia del Tribunal Constitucional Federal alemán (TCFA en lo sucesivo) que voy a describir y comentar $^{1}$, pues por un lado, no deja vacío de contenido el imperativo cons-

\footnotetext{
${ }^{1}$ Esta parte del trabajo es una síntesis del artículo de Fisahm, Andreas y Möller, Michael, "Lo Stato sociale in Germania: il Tribunale Constituzionale Federale "parla" alla politica note sulla sentenza del Tribunale Constituzionale del 9 de febbraio 2010" en Rivista Giuridica del Lavoro e della previdenza sociale, anno LXI, 2010, $\mathrm{N}^{\circ} 3$, páginas 395 y ss. Incluyo este trabajo aquí porque he podido comprobar que esta importante Sentencia es muy poco conocida entre nosotros.
} 
titucional de la dignidad humana combinado con la cláusula del Estado social, y por otro, deja margen para que sea el Gobierno y el Parlamento los que concreten el derecho.

El TCFA se ocupó en febrero del año pasado del tema fundamental de qué es lo que necesita una persona para vivir y decidió que el nivel de la prestación por desempleo, tal y como estaba previsto por la ley Hartz IV, debía ser calculado nuevamente tanto para los niños como para los adultos.

La Sentencia fue acogida favorablemente por los partidos, por las organizaciones de ayuda social y por los sindicatos. Teniendo en cuenta que las personas beneficiarias de las prestaciones que se derivan de la ley Hartz IV son casi 7 millones, el gobierno hubo de tener en cuenta la previsión de un gasto considerablemente superior.

En el momento de dictarse la Sentencia la cantidad era de 345 euros, mientras que los menores recibían una suma total que viene a ser de entre el 60 y el $80 \%$ del referido importe. Ahora bien, los jueces del TCFA consideraron que el nivel de las prestaciones para los niños y los adultos no era manifiestamente inconstitucional y que, en determinadas circunstancias podía ser considerado aceptable. En cambio es considerado inconstitucional el método de cálculo de los importes, ya que el legislador había fijado el nivel de las anteriormente referidas prestaciones mediante estimaciones. En particular, para los niños, la necesidad efectiva no es el resultado de un cálculo, si no de una simple estimación. El Tribunal Constitucional ordenó por tanto al legislador volver a calcular los importes antes del final del $2010^{2}$.

La opinión pública esperaba con impaciencia la decisión. Los detractores y los partidarios de las reformas la han interpretado en particular como una Sentencia de principio. En ella, por una parte, se valoraba la constitucionalidad de las grandes "reformas sociales": éstas, introducidas por el gobierno "rojiverde" del canciller Schröeder en el 2005 supusieron el fin político de la coalición entre SPD y verdes y muchos sostienen incluso que supusieron el fin del Estado social de la República Federal alemana. Por otra parte, estaba también la cuestión urgente del elevado número de los sujetos beneficiarios de la prestación por desempleo "II" (Arbeitslosengeld II - ALG II).

La Sentencia del Tribunal ${ }^{3}$ tuvo un impacto enorme tanto a nivel político como social. Sólo en 2006 con base a la ley Hartz IV se habían retribuido prestaciones por un total de 40.500 millones de euros. Entre tanto el gobierno Merkel temía que si los jueces juzgaban demasiado bajos los importes calculados, la sentencia podía generar un incremento de gasto insoportable.

${ }^{2}$ El Tribunal, sin embargo no emitió indicaciones en cuanto a la entidad de las prestaciones, de modo que no es seguro que los sujetos beneficiarios de las ayudas previstas por la ley Hartz IV puedan esperar obtener mayores ventajas económicas.

${ }^{3}$ Antes de la Sentencia del Tribunal Constitucional Federal ya dos tribunales habían manifestado dudas sobre el hecho de que el importe, fijado en el nivel previsto por la ley fuera suficiente. El Tribunal Social Federal planteó cuestión al TCFA por cuanto consideraba que las prestaciones ordinarias de 345 euros eran inconstitucionales . 


\subsection{Las llamadas reformas Hartz y el antiguo sistema de prestaciones.}

Antes de que el sistema de las prestaciones sociales en Alemania se modificara por la ley Hartz IV de 2005 se componía de tres elementos. Los trabajadores despedidos, y luego desempleados, percibían una prestación de desempleo. Se trataba de una prestación garantizada por un seguro (obligatorio) estatal al que los trabajadores por cuenta ajena habían contribuido con anterioridad. El nivel de las contribuciones, así como el de la prestación correspondiente dependía del último salario percibido. Además del seguro de desempleo limitado en el tiempo, las personas en busca de trabajo y los necesitados percibían la ayuda por desempleo, la cual -en los comienzos de la era republicana- se financiaba con las contribuciones de los trabajadores. Posteriormente, sin embargo, a la vista del incremento del número de parados, los fondos necesarios se obtenían únicamente del sistema general impositivo. El derecho a la ayuda para los parados era ilimitado en el tiempo y permitía al que la percibía conservar su propio ritmo de vida individual a un nivel más bajo, ya que se le abonaban prestaciones equivalentes aproximadamente a la mitad de la última retribución ${ }^{4}$. Las personas necesitadas de ayuda que no tuvieran derecho ni a la prestación por desempleo ni a la ayuda para los parados, recibían una ayuda social que les garantizaba el mínimo vital, entendido por la ley como "mínimo vital sociocultural”.

La financiación de la ayuda social derivaba, precisamente como la ayuda para los parados del sistema general de impuestos. Los beneficiarios de la ayuda social recibían prestaciones equivalentes a unos 300 euros al mes, a lo que se añadían cantidades retribuidas una tantum para compras concretas, como por ejemplo, frigoríficos, lavadoras, y también mochilas para la escuela de los niños ${ }^{5}$. El Estado, además se hacía cargo de los gastos de alojamiento y calefacción.

A partir del 1 de enero de 2005 se introdujeron importantes modificaciones del sistema social en vigor; estas, entre otras cosas llevaron, a la unificación de la ayuda para los parados con la ayuda social en la llamada ALG II (Arbeitslosengeld II). Los beneficiarios de la prestación ALG II perciben ahora como máximo 345 euros al mes, además de las prestaciones para alojamiento y calefacción. Importantes disposiciones posteriores establecen que el nivel de la prestación de ayuda ya no tenga como parámetro de referencia

${ }^{4}$ El montante de la prestación por desempleo llegaba al 53\% o al 57\% de la retribución. El parado percibía el importe más alto en caso de existencia de hijos a su cargo.

${ }^{5} \mathrm{El}$ art. 21.1.a de la ley federal sobre la ayuda social, que estuvo en vigor hasta $31 \mathrm{de} \mathrm{di-}$ ciembre de 2004, permitía la obtención de ayudas para el mantenimiento mediante prestaciones concretas: tales prestaciones podían ser obtenidas para la reparación de la ropa y los zapatos en cantidades elevadas y para la adquisición de este tipo de cosas por un total de cierta entidad, para la adquisición de material escolar o incluso para la adquisición de productos de consumo de larga duración y alto valor o para ocasiones particulares. 
la última retribución como ocurre en el caso de la ayuda para los parados, si no que se establezcan importes ordinarios de una cantidad fija. Además estas prestaciones ya no reflejan el tenor de vida individual al nivel más bajo, si no que aseguran solamente el mínimo vital del particular.

El antiguo sistema, considerado en su conjunto, prometía -como hace habitualmente un seguro- el mantenimiento de las condiciones de vida individuales. El nuevo sistema garantiza a todos, de la misma manera, un mínimo vital determinado por el Estado. Además la ley deroga las prestaciones que se hacían una sola vez para adquisiciones una tantum, por lo que, - en particular por lo que se refiere a la ayuda social- se reduce claramente la entidad de la correspondiente prestación. Los que tienen necesidad de ayuda deberán, por tanto, ahorrar para poderse garantizar las compras que antes proporcionaba el Estado.

Estas modificaciones fueron presentadas por la Comisión Hartz, cuyo nombre se deriva del de su presidente Peter $\mathrm{Hartz}^{6}$. En el fondo de la reforma de 2005 latía la convicción de la subsistencia de un rechazo del trabajo, generado por excesivas garantías sociales, por lo que las referidas garantías se suprimieron. Ejercitar presión a nivel social llevaría a un aumento a la disponibilidad para trabajar. Desde 2005 el número de parados ha disminuido de 4 a 3 millones, pero se discute mucho si se debe a la ley Hartz IV. La reforma se llevó a cabo desde uno de enero de 2005 mediante la Cuarta Ley para los Servicios Modernos en el mercado de trabajo. Por eso el subsidio ALG II es conocido en el debate público como Hartz IV ${ }^{7}$.

\footnotetext{
${ }^{6}$ Este grupo de trabajo, compuesto por economistas, representantes sindicales y políticos de relevancia fue creado en 2002 por el canciller Schröder con la tarea de elaborar una estrategia para reducir a la mitad el número de parados -que entonces era de cuato millones- en cuatro años. Además se pensaba que la unificación de la ayuda para los parados con la ayuda social, reduciría el gasto administrativo y garantizaría mayor transparencia administrativa y de gestión. También estaba presente la idea de activar la estrategia del do ut des en el marco de una "socialdemocracia modernizada". En este esquema teórico-político, el Estado no debe solamente ayudar (do) a las personas que tienen necesidad de ayuda, si no también pretender algo de ello (ut des), en la medida en que los beneficiarios del intercambio debían estar dispuestos a aceptar incluso un trabajo "peor", es decir, sobre todo menos retribuido.

${ }^{7}$ Se comprenderá que las reformas Hartz se asocian a una fuerte reducción del Estado social en Alemania, que repercutía sobre todo en el amplio ámbito de los perceptores de la ayuda para parados cuya entidad se ha reducido notablemente. Si con anterioridad los parados podían todavía contar con prestaciones equivalentes al 50\% de la última retribución, hoy, tras la reforma, reciben 345 euros al mes. Notablemente esto podía significar que el particular se veía obligado a reducir notablemente su nivel de vida para sobrevivir con los medios que se ponían a su disposición. La consecuencia es que ha crecido entre los trabajadores el temor de quedarse sin trabajo y de verse en poco tiempo con la prestación ALG II en un nivel de renta al que no están acostumbrados.

Las llamadas reformas Hartz IV han alimentado las protestas de los sindicatos y de los entes de ayuda social contra tal "paquete antisocial" de medidas de austeridad, que ha redu-
} 


\subsection{A. Contenidos de la reforma Hartz IV}

El núcleo de las reformas está constituido por la Cuarta Ley para los Servicios Modernos en el Mercado de Trabajo, que establece en primer lugar la unificación de la prestación de ayuda para los parados con la ayuda social en una única prestación denominada ALG II. A tal unificación se asocia ante todo una notable reducción del Estado social que afecta a las personas que percibían la antigua prestación por desempleo, cuyo nivel de vida se ha rebajado al nivel del umbral del mínimo vital sociocultural ${ }^{8}$

La entidad y el nivel de las prestaciones ordinarias se establecen por el legislador (art. 20.1 III del SGB II). La prestación ordinaria comprende en particular los siguientes costes: alimentación, vestido, cuidado del cuerpo, ajuar doméstico, exigencias de la vida cotidiana, así como, en medida sostenible, también las relaciones con el ambiente y la participación en la vida cultural. El cabeza de familia y las personas que viven solas perciben el $100 \%$ de la suma ordinaria (345 euros). Si dos adultos capaces de trabajar viven juntos, formando un núcleo familiar necesitado, reciben en conjunto el $180 \%$ del importe ordinario (621 euros). Para los hijos se prevé una reducción del 40\% del importe (207 euros) hasta que cumplen 14 años. Una vez que cumplen los 14 años la reducción sobre el importe ordinario es del 20\% (276 euros).

cido a la pobreza amplias capas de la población alemana. La resistencia de los sindicatos y de los entes de ayuda social de todas formas ha ido disminuyendo. La insatisfacción de la población se manifestó en las derrotas electorales del SPD, que había promovido las reformas durante el gobierno del canciller Schröeder. No ya elementos de la izquierda del partido, sino incluso parte del núcleo tradicional, se han separado del SPD y se han dirigido a la Linke, nacida del PDS (Partei des Demokratischen Sozialismus). Así lo prueba no sólo el aumento de su número de afiliados sino también el incremento de votos recibidos por este último partido.

${ }^{8}$ Con la ley de reforma, cuya entrada en vigor rige desde 1 de enero de 2005, se introdujo el Libro Segundo del Código Social (Sozialgesetzbuch Zweites Buch-SGB II) -garantía fundamental para los que buscan trabajo-, en el que se establece un conjunto de garantías normativas medidas en función del nivel de las necesidades de los capaces de trabajar y de los que conviven en una comunidad necesitada. Según el Código Social II (SGB II) tienen derecho a la prestación ALG II, en primer lugar, todos los sujetos de edad comprendida entre los 16 y los 65 años, que necesiten ayuda, capaces de trabajar y que residan habitualmente en Alemania. Además, tienen derecho a las prestaciones también los sujetos capaces de trabajar que viven en lo que se llama una comunidad necesitada con sujetos que necesitan ayuda. Se trata, por ejemplo, del cónyuge o de los hijos menores no casados, en la medida en que no perciban una renta suficiente para el propio mantenimiento. Los no capacitados para trabajar, o no pertenecientes a una comunidad necesitada, perciben la prestación ALG II según el Libro XII del Código Social (Sozialgesetzbuch Zwölftes Buch).

Los sujetos necesitados de ayuda reciben la prestación ALG II como cantidad ordinaria para garantizar su sustento, e incluidos gastos proporcionados de alojamiento y calefacción (art. 19. SGB II). Solo en casos excepcionales, expresamente previstos, la ley establece prestaciones pecuniarias una tantum (Art. 23 III.SGB II. Entre estos casos excepcionales se incluyen: la adquisición inicial de muebles para apartamentos (incluidos los electrodomésticos), la adquisición inicial de vestimenta también caso de gravidez y parto, así como las excursiones escolares). 


\subsection{B. Cálculo de la prestación ordinaria}

Desde el punto de vista de la determinación de la prestación ordinaria, suficiente para garantizar el mínimo vital, existen fundamentalmente dos métodos de cálculo diversos para establecer en términos abstractos la necesidad mensual de dinero.

A partir de 1962, los importes ordinarios en el ámbito de la ayuda social se han determinado con base en el llamado modelo de la cesta, consistente en establecer por hipótesis una cesta de bienes medida sobre la base de las costumbres vitales y de consumo de las franjas de renta inferior.

Se valoraban los bienes de los que tiene necesidad un núcleo familiar compuesto por dos adultos con renta limitada, que percibe la pensión o la prestación de ayuda social. Los costes de tales hábitos de vida y consumo se calculan concretamente en razón del precio de los bienes al que se ha hecho referencia y sobre la base del mismo se establecen los importes ordinarios.

Desde 1990, sin embargo, se fijan con base en unos patrones de renta y consumo ${ }^{9}$. El antiguo sistema de prestaciones de la ayuda social, en el que se calculaban los importes ordinarios con base en unos patrones de renta y consumo, preveía - para necesidades excepcionales que no se repetían- contribuciones estatales una tantum que se añadían a las prestaciones. Con la unificación de la prestación de desempleo con la prestación de ayuda social, este sistema de cálculo se mantiene pero las prestaciones una tantum por necesidades excepcionales (según el Libro II del Código Social) no se devengan. El importe ordinario calculado, sin embargo, se aumenta para el tipo de ne-

\footnotetext{
${ }^{9}$ Para ello, cada cinco años, en Alemania se consulta a sesenta mil núcleos familiares elegidos, por lo demás, según una tipología de núcleo familiar, la posición social del perceptor de la renta principal y la renta neta del núcleo familiar. Durante la recogida los núcleos familiares que participan voluntariamente anotan durante tres meses todas las entradas y salidas en un presupuesto establecido a este propósito. Cada cuatro núcleos participantes, hay un quinto que tiene una libreta de anotaciones, en la que durante un mes registra de manera detallada todas las salidas para los alimentos, bebidas y tabaco, anotando la cantidad y precio de los mismos. Para el cálculo del importe ordinario uno se basa en los gastos para consumo del $20 \%$ inferior de los núcleos familiares clasificados con base en la renta neta. La determinación de este grupo de referencia se realiza de acuerdo con una decisión política. A diferencia del modelo de la cesta, no se tiene en cuenta todos los gastos efectuados por este grupo de referencia, si no sólo algunas partidas. Esto provoca que en el cálculo de la prestación ordinaria no se tomen en consideración las necesidades una tantum y las que se consideran típicas de la prestación de ayuda social. Con este modelo estadístico, el importe ordinario se fija por tanto únicamente según el consumo de las franjas inferiores de renta. Además, la base de cálculo también se restringe en el sentido de que no se reconocen determinados gastos. Si se consideraran todas, el importe ordinario se situaría en torno a los 779 euros al mes. Como este modelo estadístico tiene en cuenta, por el momento, solamente los núcleos familiares compuestos por una persona, para los ulteriores miembros del núcleo se ha elaborado un sistema para deducir indirectamente los importes ordinarios según un cálculo diferenciado modificado. Sobre tal base se produce una relación porcentual sobre el importe ordinario para los núcleos unifamiliares.
} 
cesidad anteriormente cubierto por prestación de ayuda una tantum.

La siguiente tabla indica qué gastos han sido considerados como base de cálculo para establecer el importe ordinario de 345 euros (situación correspondiente al año 2003). V. tabla en la página siguiente.

Se puede compartir la estrategia de fondo de la reforma, basada en la unificación de la prestación de desempleo con la prestación de ayuda social, y por tanto en la exclusión de un derecho al mantenimiento del nivel de vida individual.

Quien, a lo largo de su actividad laboral ha sido bien o muy bien retribuido, debería, una vez transcurrido un tiempo prolongado, no tener ningún derecho a ser mantenido en un nivel elevado por el sistema impositivo general. Se puede compartir la idea de que cada persona reciba del Estado una misma cantidad para el sustento. El antiguo sistema de la garantía del nivel de vida presentaba diversidad de condiciones con cargo a la colectividad.

\begin{tabular}{|c|c|c|c|}
\hline Tipología & Cuota & Exclusiones & $\begin{array}{c}\text { Importe } \\
\text { (redondeado) }\end{array}$ \\
\hline $\begin{array}{l}\text { Alimentos, bebidas } \\
\text { y tabaco. }\end{array}$ & $96 \%$ & El gasto de tabaco se calcula solo al $50 \%$. & $127 €$ \\
\hline Vestido y zapatos. & $89 \%$ & Vestidos a medida, pieles, vestimenta de trabajo. & $34 €$ \\
\hline Vivienda. & $8 \%$ & Alquiler y calefacción. & $26 €$ \\
\hline $\begin{array}{l}\text { Muebles y ajuar } \\
\text { doméstico. }\end{array}$ & $87 \%$ & Muebles para acampar y objetos de arte. & $25 €$ \\
\hline Ayuda sanitaria. & $64 \%$ & $\begin{array}{l}\text { Prestaciones sanitarias con recuperación hospitala- } \\
\text { ria, prestaciones odontológicas. }\end{array}$ & $13 €$ \\
\hline Circulación & $37 \%$ & Gastos para automóviles, motocicletas y reparaciones & $16 €$ \\
\hline $\begin{array}{l}\text { Correo, teléfono e } \\
\text { internet. }\end{array}$ & $64 \%$ & $\begin{array}{l}\text { Costes para aparatos telefónicos y fax al 50\%, ser- } \\
\text { vicios de telefonía y fax al } 60 \% \text { y costes de internet } \\
\text { en parte. }\end{array}$ & $30 €$ \\
\hline $\begin{array}{l}\text { Tiempo libre, espar- } \\
\text { cimiento, cultura. }\end{array}$ & $42 \%$ & $\begin{array}{l}\text { Embarcaciones deportivas, ala delta, aparatos foto- } \\
\text { gráficos y cinematográficos, soportes audiovisua- } \\
\text { les, animales de compañía. }\end{array}$ & $39 €$ \\
\hline Educación & $0 \%$ & $\begin{array}{l}\text { Gastos de conjunto no pertinentes a efectos del im- } \\
\text { porte ordinario. }\end{array}$ & $0 €$ \\
\hline $\begin{array}{l}\text { Consumiciones y } \\
\text { hospedajes noctur- } \\
\text { nos. }\end{array}$ & $30 \%$ & $\begin{array}{l}\text { Se considera solamente la cuota relativa a los ali- } \\
\text { mentos. }\end{array}$ & $8 €$ \\
\hline $\begin{array}{l}\text { Otros costes para } \\
\text { bienes y servicios. }\end{array}$ & $65 \%$ & Joyas y metales preciosos, multas. & $27 €$ \\
\hline Total & & & $345 €$ \\
\hline
\end{tabular}

La cuestión fundamental sigue siendo, de todas formas, la del nivel que debe tener el importe para garantizar al individuo un mínimo vital digno. De 
esto se tuvo que ocupar el Tribunal Constitucional. Se trataba de valorar si el importe ordinario de 345 euros satisfacía o no lo imperativos constitucionales. La experiencia, en todo caso, demuestra que un devengo que alcanza como máximo los 345 euros mensuales es claramente insuficiente.

El Tribunal Constitucional no tenía sin embargo que juzgar con base en la experiencia, sino referirse a normas constitucionales.

\subsection{Sentencia del Tribunal Constitucional Federal Alemán.}

El Tribunal Constitucional tenía que decidir si las modalidades de cálculo de las prestaciones ordinarias de 345 euros y las reducciones practicadas para los niños y los jóvenes eran compatibles con la Constitución.

El Tribunal no examinó la cuestión de si el nivel efectivo de la prestación era suficiente, porque consideraba que no era manifiestamente inconstitucional. En cambio se ha planteado el problema de si los gastos necesarios para la subsistencia han sido el resultado de un procedimiento transparente y congruente, así como comprensible, fundado en datos fiables y métodos de cómputo convincentes.

El control, por tanto, tenía por objeto el método de cálculo y los factores a considerar en el mismo. No se trataba, por tanto, de responder a la pregunta de si la arquitectura de las reformas era inconstitucional o no, porque la cuestión no era valorar la unificación de la prestación de desempleo con la prestación de ayuda social. El examen del resultado de tal cálculo, es decir, el nivel de la prestación, se redujo a la verificación de los criterios utilizados.

Habría sido deseable -y esto habría entrado en el marco de la interpretación jurídica- que el Tribunal Constitucional hubiera ofrecido contribuciones concretas o hubiera indicado al menos estándares mínimos que no pudiera sobrepasar el legislador para la prestación ordinaria adecuada para garantizar un mínimo vital. La cuestión crucial en términos de presupuesto así como en términos de impacto social -es decir, cuanto vale para el Estado una vida digna- se ha reenviado por parte del Tribunal Constitucional a la política.

Se reconoce que corresponde al legislador la tarea de determinar la cuantía de la prestación. El legislador está legitimado para asumir decisiones políticas en el ámbito de un marco de referencia constitucional. La Ley Fundamental (LF, en lo sucesivo) contiene principios que, en el caso de la seguridad social se pueden condensar en un derecho fundamental, pero ciertamente no se dejan concretar en cifras. Sin embargo el modelo de cálculo -el método para determinar el mínimo vital sociocultural- se ha aceptado por el TCFA sin un examen suficiente, considerándolo fundamentalmente justo y no claramente inconstitucional.

\section{A. Derecho fundamental a la "garantía de un mínimo vital digno"}

El Tribunal Constitucional ha examinado, por tanto, la determinación de los importes ordinarios a la luz del "derecho fundamental" establecido por la 
LF “a la garantía de un mínimo vital digno”. Por tanto los jueces elevan expresamente tal derecho al rango de derecho constitucional fundamental, que con anterioridad nunca había sido empleado como criterio de control. Y en efecto, ni siquiera podía haberlo hecho, porque la Constitución alemana no reconoce un derecho fundamental, explícitamente formulado como tal a un mínimo vital digno, sino que se declara explícitamente a favor del Estado social (art. 20) y tutela la dignidad humana como valor constitucional supremo.

Desde el punto de vista del método, el Tribunal recorre un camino ya recorrido otras veces. Condensa una orientación jurisprudencial ${ }^{10}$, que ha expresado hasta la actualidad problemas análogos de fondo, en un derecho fundamental que no se había planteado nunca de esta forma. El Tribunal funda el nuevo derecho fundamental sobre el valor de la dignidad humana (art. 1 LF) relacionándolo con el principio del Estado social (art. 20), delegando al legislador la tarea de garantizar a cada uno un mínimo vital digno. Hasta la actualidad los jueces que se pronunciado sobre el fondo del asunto, habían fundado en la combinación de los dos artículos de la Ley Fundamental el deber del Estado a la ayuda a los necesitados como presupuesto mínimo para una existencia digna. Que el Tribunal Constitucional Federal eleve ahora tal derecho al rango constitucional es algo que se debe valorar muy positivamente.

Añádese a esto que el derecho a una existencia digna fundado en el art. 1 se considera "intangible" y vinculante para el legislador, que garantiza la realización concreta del mismo. Además, tal derecho resulta revalorizado por el hecho de que el particular puede reclamar contra su violación por medio de un recurso constitucional.

Sin embargo, tal revalorización no se puede considerar en sí misma equiparable a un aumento de las prestaciones sociales y a la mejora de la condición social del beneficiario de las mismas. Además los jueces constitucionales explican que el derecho fundamental sería sustancialmente indisponible, "pero la concretización y la actualización constante por parte del legislador requiere que este último deba ajustar periódicamente las prestaciones a devengar al nivel de desarrollo de la comunidad de las condiciones de vida existentes" (STCFA de 9 de febrero de 2010, líneas 133 y ss).

El derecho fundamental a las prestaciones creado recientemente es objeto de una reserva de ley que regula los aspectos organizativos del mismo. Tampoco sería admisible una solución distinta, porque, desde el punto de vista de la legitimación democrática es fundamentalmente justo que la organización de una garantía jurídica se deje al legislador y no a los jueces. Para la realización concreta de los derechos siempre es necesaria una ley, y el legislador puede ejercitar su discrecionalidad al considerar qué nivel de prestaciones

${ }^{10}$ Cfr TCF 40, 121 Vgl. BVerfGE 40, 121 (131). Limitación en el tiempo de la pensión a los huérfanos; 82, 60 (85): reducción de prestaciones familiares; 113, 88 (108 ss): mantenimiento de los padres. 
considera suficiente para garantizar un mínimo vital digno. Por tanto se puede valorar el ejercicio de la discrecionalidad legislativa a la luz de las normas constitucionales sólo en caso de evidentes violaciones del derecho a una existencia digna y de vicios procedimentales.

Como el Tribunal Constitucional excluye una violación evidente, ya no es necesario controlar el nivel de las prestaciones. El Tribunal dice que: "para determinar la entidad del derecho, el legislador debe calcular todos los gastos necesarios para el sustento con un procedimiento transparente y objetivo, realista y susceptible de ser compartido, basado en datos fiables y métodos de cómputo convincentes" (STCFA de 9 de febrero de 2010, criterio 3 y línea 139).

Por tanto considera que solamente un procedimiento correcto y transparente puede producir decisiones "justas".

El derecho fundamental, por una parte, tutela la existencia física del particular, en el momento en que se le ofrece la posibilidad de procurarse alimentos, vestido y ajuar doméstico o tener una casa. Por otra parte, el mismo derecho contiene también un derecho al cuidado de las relaciones interpersonales y a una mínima participación en la vida política, cultural y social. Se trata por tanto de un mínimo vital sociocultural. A nivel constitucional la persona debe considerarse un zoon politicon, un ser social, porque la existencia mínima en una sociedad democrática se completa con la participación en el proceso político.

Y la persona se concibe como ser social, comunicativo, que puede realizar la propia personalidad sólo en sociedad y en comunidad con otros y en contacto con la producción cultural de la sociedad a la que pertenece. Si, en principio, de la carta constitucional se puede derivar tal derecho, no deriva de ella ninguna indicación respecto de qué medios financieros son necesarios para su goce, ni sobre qué exigencias mínimas deben ser satisfechas. Por eso, repetimos, el derecho fundamental para la realización concreta depende del legislador.

\section{B. Prestación ordinaria fijada de manera inconstitucional}

La mayor desilusión provocada al beneficiario de la prestación ALG II por la sentencia a la que nos venimos refiriendo, debería consistir en la convicción del Tribunal de que una prestación ordinaria de 345 euros mensuales no es claramente insuficiente. Además los jueces no han objetado nada respecto del hecho de que los costes para las necesidades una tantum se hayan considerado en su conjunto e incluidos en el importe ordinario. También estaría sustancialmente en línea con la Ley Fundamental la decisión del legislador de escoger como base de cómputo el nuevo modelo estadístico. De ello se sigue que es correcto escoger tal enfoque metodológico y establecer que el grupo de referencia esté constituido por el $20 \%$ inferior de los núcleos familiares clasificados con base en la renta neta. 
El Tribunal, en efecto, considera que el modelo estadístico es “un método constitucionalmente admisible, como método razonable para la determinación de un mínimo vital coherente con la realidad"11.

Además, el modelo estadístico y de consumo ofrecería respecto del "método de la cesta también la ventaja de que no establece el mínimo vital más allá del cual la garantía de la supervivencia física con base en los diferentes conceptos de necesidad seleccionados individualmente pero, junto al mínimo vital mide los gastos necesarios para garantizar un mínimo de participación social con base en el comportamiento efectivo de gasto" 12 .

Los jueces han manifestado algunas dudas de naturaleza constitucional en relación con la prestación ordinaria fijada para los jóvenes, los niños y los adultos: no porque sea demasiado baja, si no por sus vicios procedimentales. El cálculo del importe ordinario -según los jueces- está viciado por un defecto de procedimiento ya que el legislador en algunos puntos se ha alejado de la estructura del modelo estadístico sin una razón objetiva evidente. En efecto, ha introducido algunas reducciones sin motivo, o ha efectuado valoraciones sin una base suficiente de datos objetivos.

Para el cálculo del importe ordinario, el legislador habría practicado reducciones porcentuales por bienes y servicios no relevantes a los fines de la prestación, sin ni siquiera dejar claro si el $20 \%$ de los núcleos familiares ha soportado tales gastos. Estos incluyen gastos para pieles y vestidos a medida, mobiliario para acampar y objetos de arte, aparatos de fax, embarcaciones deportivas y alas delta. El absurdo es evidente: los sujetos que se encuentran en la franja del $20 \%$ inferior de renta no gastan en la adquisición de pieles o alas delta. Los gastos para tales objetos de lujo se han estimado -dado que obviamente no constan en los libros contables de los núcleos familiares- y se ha restado tal cuota, porque no sirve para garantizar el mínimo vital.

Se han criticado en particular las reducciones para los gastos de energía eléctrica, para la necesidad de movilidad, así como la completa exclusión de los gastos de educación. En conjunto, de los gastos reales del $20 \%$ inferior de los núcleos familiares - estimados por el legislador- se ha practicado una reducción del 56\%. Por tanto, los consumos relevantes para los fines de la prestación no se han constatado en absoluto de manera coherente ${ }^{13}$.

En la base de tal reducción hay además una definición política discutible de los niveles, con la que se debería respetar la obligación de la diferencia salarial. En principio, los beneficiarios de ayuda social deberían estar peor que las personas que tienen un trabajo mal pagado. Pero, sin embargo, la retribución de las franjas de renta inferior está por debajo del mínimo vital, y, si las franjas de renta inferior para aumentar esto, además del salario perciben las

\footnotetext{
${ }^{11}$ STCFA, línea 163.

${ }^{12}$ STCFA, línea 166.

${ }^{13}$ STCFA, 9 de febrero 2010, línea 175.
} 
prestaciones previstas por la ley Hartz IV, el modelo de cálculo, a pesar de la necesaria discrecionalidad política, crea problemas. Se establece un círculo vicioso: el sistema Hartz IV genera dumping salarial y calcula el mínimo vital de las franjas de renta, que de esta manera quedan clasificadas como más bajas. El Tribunal Constitucional, con su ofuscación respecto de la realidad económica, no ha tenido en cuenta tales consecuencias en el sistema social.

Con referencia a los niños y a los jóvenes, el legislador -según el Tribunal Constitucional- habría practicado una reducción del $40 \%$ y del $20 \%$ respectivamente; sin que, sin embargo, se haya calculado verdaderamente la necesidad efectiva de tales sujetos. Por tanto, el legislador no ha considerado ni el desarrollo de la personalidad específico del niño ni los gastos para el cumplimiento de las obligaciones escolares, como necesidades incluidas en el mínimo vital. El legislador no puede estimar la necesidad efectiva de jóvenes y niños, y no puede ni siquiera tratarlos como si fueran "pequeños adultos", practicando simplemente reducciones sobre el importe ordinario previsto para los adultos. Sin la cobertura de los costes de los gastos necesarios para el cumplimiento de las obligaciones escolares, "el riesgo para los niños necesitados es que se vean impedidos de las posibilidades vitales". La reducción del importe ordinario para niños y jóvenes lleva a consecuencias absurdas: a nivel de puro cómputo, un bebé dispone de dinero para comprar cerveza pero no pañales.

Y, siempre según la ley, el joven de diecisiete años en pleno crecimiento tiene un apetito equivalente al $80 \%$ del de la madre. Al no estar previstos recursos económicos para la educación de los adultos, faltan los mismos para los hijos. Esto es lo que ocurre cuando se trata a los niños y a los jóvenes como si fueran "pequeños adultos".

\section{Derecho a la prestación en casos de necesidad atípicos}

Hasta ahora, la legislación no ha previsto pagos extraordinarios en los casos en que los beneficiarios de las prestaciones tengan necesidades de ayudas económicas para necesidades atípicas. A raíz de la introducción de las reformas Hartz, estas ayudas ya no están aseguradas, sosteniéndose que para tales adquisiciones atípicas ya se contiene una contribución en los importes ordinarios. A quien tiene necesidad de ayuda, se le da la indicación de apartar dinero, obteniéndolo de las prestaciones mensuales ALG II para sustituir, por ejemplo, una lavadora defectuosa, o para otras eventualidades de este tipo.

El Tribunal Constitucional ha decidido que todos los beneficiarios de las prestaciones tienen un derecho, derivado directamente de la Constitución, a prestaciones que tienen por finalidad garantizar una necesidad de naturaleza extraordinaria inderogable, actual, y no solo una tantum. Ésta debe ser necesariamente satisfecha para garantizar un mínimo vital digno. Por tanto, en el futuro, el legislador no está obligado a garantizar prestaciones especiales con las que los beneficiarios puedan comprarse una lavadora o un abrigo durante 
un invierno frío. En cambio, del conjunto de los arts. 1.1 y $20.1 \mathrm{LF}$, se deriva un derecho a la prestación, por ejemplo, en los casos en que la persona necesitada de ayuda, a causa de una enfermedad crónica necesite continuamente fármacos cuyo gasto deba sostener. Que tal derecho debe ser garantizado resulta precisamente del hecho de que tales "hábitos de vida y consumo" no están incluidos en el modelo y, por tanto, el legislador no puede imponer al particular crear reservas para tales eventualidades atípicas.

\subsection{Consecuencias de la sentencia}

La sentencia del Tribunal Constitucional Federal deja al legislador la posibilidad de confirmar, en función del nivel, la prestación ordinaria devengada hasta ahora, siempre y cuando motive mejor el objetivo de la misma. Incluso una reducción de las prestaciones ordinarias por la relativa motivación podría eventualmente ser conforme a la Constitución, porque ni el método de cálculo ni la obligación de la diferencia salarial han sido cuestionados.

El legislador debía fijar las prestaciones ordinarias de conformidad con la Ley Fundamental antes del 1 de enero de 2011. Esto excluye la posibilidad de que los destinatarios de las prestaciones puedan contar con devengos que las completen.

Causa perplejidad, ante todo, que los beneficiarios de la prestación ALG II hayan percibido hasta ahora prestaciones cuya entidad ha sido inconstitucional desde el principio. Como los jueces no han podido determinar con base a la Ley Fundamental un nivel efectivo, indicando el importe de la prestación necesario para garantizar el sustento, tampoco han podido obligar al Estado a completar la eventual diferencia sobre las sumas pagadas en el pasado a las personas necesitadas de ayuda.

Merecen ser acogidas favorablemente las declaraciones de los jueces relativas al derecho y a las prestaciones en caso de necesidad atípicos. El legislador tendría tiempo hasta el 31 de diciembre de 2010 para definir una nueva normativa al respecto y, hasta la entrada en vigor de ésta, el derecho derivaría directamente de la Constitución.

Para medir la prestación ordinaria el legislador puede por otra parte escoger el modelo estadístico que toma como referencia las costumbre de vida y de consumo de los núcleos familiares de las franjas de rentas inferiores.

El legislador debe solamente tener cuidado en pesar correctamente los gastos necesarios al sostenimiento y atribuir sólo la justa importancia. Debe justificar objetivamente las reducciones y hacer conocido el método de cómputo. La nueva determinación de la prestación ordinaria no debería sin embargo significar necesariamente que esta se aumente.

Aunque el legislador fije el nivel de las prestaciones de conformidad con la Constitución, esto no significa que no pueda cambiar el nivel de las prestaciones, si bien de forma motivada. Las "crueldades políticas" sostenidas por la mayoría en el Parlamento deben ahora ser planteadas a la opinión pública 
haciendo creer que pueden ser presentadas al Tribunal como decisiones motivadas racionalmente.

En el debate político, la sentencia de la que venimos hablando ha ofrecido a los medios gubernamentales un motivo para poder discutir públicamente del ulterior desmantelamiento del Estado social. En las filas de la CDU, después de la sentencia, se han levantado voces que pedían una reducción del importe ordinario previsto por la ley Hartz IV. El presidente del grupo parlamentario de la CDU en el Bundestag, Peter Weiss ha afirmado: "El Tribunal Constitucional Federal no ha dicho que los importes de la Hartz IV sean demasiado bajos". Según él, una reforma debería llevar a importes ordinarios más bajos. Los políticos del FDP están de acuerdo, y han visto en la sentencia del Tribunal Constitucional una ocasión "para poder hablar del conjunto de las reformas de las ayudas sociales. Modificaciones apresuradas no nos ayudan a progresar". "Sería justo", ha afirmado el secretario general de la FDP, Lidner, "que el Estado comenzase por los niños pero no con contribuciones en efectivo para los padres. No quisiera que con un nuevo sistema se crearan incentivos en virtud de los cuales las personas puedan ganar dinero teniendo hijos"14.

En el debate no se reconoce que la Sentencia no ofrece orientaciones para reducir el nivel del importe ordinario, si no que confía a la política la tarea de ocuparse de definir correctamente, una vez más, el umbral de la pobreza en Alemania, indicando toda una serie de criterios con base en los cuales el legislador puede crear leyes sociales "mejores".

A pesar de la reticencia mostrada respecto de las explicaciones relativas al nivel del importe ordinario, la Sentencia merece ser acogida favorablemente. Se proporcionan al legislador criterios, sin fijar sin embargo indicaciones políticas. Es además positivo que se proclame "un derecho fundamental

${ }^{14}$ El 5 de julio de 2010 el Ministro de Trabajo, Von der Leyen, señaló en una conferencia de prensa que los niños beneficiarios de la Hartz IV serán asistidos en el futuro con mejores "servicios y prestaciones en especie". El ministro también afirmó que: "la decisión de no pagar una prestación pecuniaria dirigida a la familia ya se ha tomado, pero haremos de manera que la ayuda vaya directamente a los niños”. Esto significa que en adelante no se dará dinero efectivo a las personas.

El presidente del FDP, así como el Vicecanciller y Ministro de Exteriores, Guido Westerwelle, ha señalado en la discusión sobre el aumento del importe ordinario la existencia de "ecos de socialismo". "Prometer a la población bienestar sin esfuerzo es una invitación a la decadencia tardo-romana". Según Westerwelle, no se trata de juzgar la cuestión de quién recibe más prestaciones estatales. En el centro de la discusión debería estar las prestaciones de los contribuyentes. "Esta inversión de la marcha es para mí el núcleo del giro político y mental, que yo, tras la discusión sobre la decisión tomada en Karlsruhe, considero más necesaria que nunca".

Entretanto, el Ministro de Finanzas, Schauble ya incluyó cuatrocientos ochenta millones de euros en el presupuesto de la enseñanza para poder financiar anteriores prestaciones para los niños beneficiarios de la Hartz IV. A nivel de puro cómputo, el importe de la Hartz IV aumenta, para cada uno de los 1,7 millones de niños, en 23 euros al mes. 
a la garantía de un mínimo vital" que permita a cualquiera poderse oponer judicialmente a la violación de la propia "dignidad social". Los beneficiarios de prestaciones sociales, por tanto, no dependen de la limosna del Estado, sino que tienen un derecho, accionable judicialmente, a la garantía de un mínimo vital digno. Tal derecho, reconocido en principio a nivel jurídico, en plena crisis económica -la más grave desde 1929- tiene una importancia que nunca se podrá apreciar suficientemente. El desarrollo posterior no es previsible; no es improbable que haya una larga fase de paralización, que podría llevar a una reordenación del sistema social. En tal situación, una vez más, ha de subrayarse la importancia de la "creación" de un nuevo derecho fundamental a un mínimo vital sociocultural. Esto impide a los tribunales de instancia adecuar la propia jurisprudencia a la situación social y suavizar los derechos de tutela.

La reticencia del Tribunal Constitucional a establecer una necesidad mínima es expresión del principio de la separación de poderes, de control recíproco de los órganos del Estado. El Tribunal ha controlado si el legislador ha cometido errores. Pero con la Sentencia no se pretende establecer la futura estructura del sistema social en Alemania. La tarea de decidir al respecto se reenvía al legislador. Más que dar indicaciones concretas, el Tribunal proporciona criterios al legislador.

Se puede, en este punto, criticar la reticencia de los jueces constitucionales a indicar cifras concretas relativas al nivel de las prestaciones, pretendiendo que especifiquen el importe necesario para garantizar el sustento. Es criticable, sin embargo, que la política haga referencia a la Sentencia sólo para recitar siempre el mismo eslogan: "el esfuerzo se premia, el que trabaja debe tener más que quien es financiado por el Estado". Aunque esto sea justo en principio, hay que decir que con este comportamiento la política no cumple la tarea que le asigna el Tribunal.

En última instancia, el punto no es usar impropiamente la Sentencia como pantalla sobre la que proyectar la política de los partidos y sobre la cual cada uno deba examinar su propia ideología política. Es, al mismo tiempo un honor y una carga crear leyes "mejores" y más justas para respetar los imperativos constitucionales y satisfacer también las exigencias de los ciudadanos, al servicio de los cuales debe estar la política.

El Estado social debe ser tomado en serio y la Sentencia tiene también este mérito.

Un Tribunal Constitucional que declara un error del legislador debe ser respetado por la política. Su pronunciamiento no debe ser usado impropiamente para desmantelar el Estado social. Tal interpretación destruye la estructura social nacional. Esto es lo que pondría en peligro a Alemania, y no el considerar que el aumento del importe ordinario sea una forma de decadencia tardorromana. Sin esfuerzo, en efecto, no hay bienestar, y ciertamente, no con trescientos cuarenta y cinco euros. 
Sentencia del Tribunal Constitucional Federal de la República Federal Alemana de 9 de Febrero de 2010, Primera Sección. Texto del CoMUNICADO DE LA OFICINA DE PRENSA DEL TRIBUNAL CONSTITUCIONAL FEDERAL DE 9 DE FEBRERO DE 2010.

Renta mínima garantizada - prestaciones ordinarias devengadas según el Libro II del Código Social - incompatibilidad con la Ley Fundamental

El derecho fundamental a la garantía de un mínimo vital digno, que se deriva del art. 1.1 LF (Grundgesetz-GG) en relación con el principio del Estado social del art. 20.1 LF, garantiza a toda persona necesitada las condiciones materiales que son indispensables para su existencia y para un mínimo de participación en la vida social, cultura, y política. El derecho es absoluto, pero el Parlamento goza de márgenes de discrecionalidad para dar a tal derecho una forma concreta. Tal discrecionalidad, sin embargo, se ejercita sobre la base de un método de cómputo de las prestaciones debidas idóneo y transparente según la necesidad efectiva, es decir, adecuado a la realidad. Las necesidades de naturaleza extraordinaria de los sujetos necesitados también deben ser cubiertas.

\section{Hechos.}

1. Con eficacia a partir del 1 de enero de 2005, la Cuarta ley para los Servicios Modernos sobre el Mercado de Trabajo (Viertes Gesetz fur moderne Dienstleistungen am Arbeitsmarkt) de 24 de diciembre de 2003 (la llamada ley Hartz IV) estableció la unificación de la ayuda para los desempleados con la ayuda social en la llamada ALG II (Arbeitslosengeld II), dando lugar a una prestación de base uniforme, previa verificación patrimonial para los sujetos capaces de trabajar y las personas que convivan con ellos dentro de un mismo núcleo familiar (comunidad necesitada). Por tanto, las personas necesitadas capaces de trabajar perciben ahora la prestación de desempleo (ALG II), y las personas a su cargo, que no sean capaces de trabajar, y que convivan en el mismo núcleo familiar, en particular, los menores por debajo de los quince años, reciben la prestación de ayuda social. Tal prestación ALG II consta esencialmente de la prestación ordinaria para garantizar el sustento, establecida por los artículos 20 y 28 del Libro II del Código Social (Sozialgesetzbuch Zweites Buch - SGB II), a las que se añaden las prestaciones para alojamiento y calefacción. Estas prestaciones se aseguran cuando no se dispongan de medios propios, en particular, renta o patrimonio. En el momento de su entrada en vigor, el Código Social II fijó en trescientos cuarenta y cinco euros el importe de la prestación ordinaria para las personas que viven en las "antiguas" regiones de Alemania occidental, incluido Berlín Este. El Código Social establece, además, la prestación ordinaria para los restantes miembros del mismo núcleo familiar, calculando un porcentaje del referido importe. Por tanto, a partir del 1 de enero de 2005, el importe para el cónyuge o la persona 
que conviva es de trescientos once euros (noventa por ciento), el importe para los niños de menos de catorce años es de doscientos siete euros (sesenta por ciento), y el importe para los jóvenes, a partir de los quince años, es de doscientos setenta y seis euros (ochenta por ciento).

A diferencia de lo dispuesto por la anterior ley federal sobre ayuda social (Bundessozialhilfegesetz - BSHG), la prestación ordinaria, según el Código Social II se devenga prevalentemente como suma global; se excluye cualquier aumento para una necesidad cotidiana. Sólo en casos excepcionales se prevé una prestación una tantum, para una necesidad de naturaleza extraordinaria. Para satisfacer una necesidad que se repite en el tiempo, pero no regularmente, se aumenta la prestación ordinaria para permitir a quien la percibe apartar el importe necesario.

2. a) Al fijar la prestación ordinaria, el Parlamento hizo referencia a la Ley Federal sobre la Ayuda Social que, desde el 1 de enero de 2005, se refundió en el Libro XII del Código Social (Sozilgesetzbuch Zwölfes Buch). Según el SGB II y el decreto sobre el importe ordinario dictado por el ministerio federal competente, la estimación de los importes ordinarios según la Ley sobre la Ayuda Social se efectúa sobre la base de un modelo estadístico que fue elaborado cuando estaba en vigor la propia ley federal sobre la ayuda social. La base para la estimación de los importes ordinarios es la valoración particular del estudio de patrones de renta y consumo, realizado cada cinco años por el Instituto Federal de Estadística. Lo que es relevante a fines de la determinación del importe ordinario de base -que vale también para los individuos- es el gasto -indicado en las diferentes secciones del estudio de patrones- del veinte por ciento inferior de los núcleos unifamiliares clasificados con base en la renta neta (la franja más baja), tras haber excluido a los beneficiarios de la prestación de ayuda social. Al valorar el importe ordinario de base, sin embargo, no se han considerado todos los gastos; en efecto, sólo algunos porcentajes de gasto se consideraron relevantes a los efectos del importe ordinario. El importe ordinario de base, que está en vigor desde el 1 de enero de 2005, se basa en el estudio de patrones sobre renta y consumo de 1998. Para determinar los gastos relevantes a fin del importe ordinario del art. 2.2 del Decreto sobre el Importe Ordinario, no se considera la sección 10 (educación) del estudio de patrones de renta y consumo. Se practican ulteriores reducciones, por ejemplo, en la Sección 03 (vestido y zapatos), por ejemplo, para las pieles y vestidos a medida; en la sección 04 (habitación) en relación al gasto de electricidad; en la sección 07 (transporte) para los costes de los vehículos a motor; y en la sección 09 (tiempo libre, esparcimiento y cultura), por ejemplo, para las alas delta. El importe calculado para 1998 se proyectó al 1 de enero de 2005 con base en las disposiciones que se aplican para la actualización anual de la prestación ordinaria del SGB II y de los importes ordinarios del SGB XII, según el actual coeficiente de las pensiones del Plan Legal de Pensiones (art. 68 SGB VI); 
b) para fijar la prestación ordinaria para los menores, el Parlamento se alejó de los porcentajes que estaban en vigor según la Ley Federal sobre Ayuda Social, creando solamente dos grupos de edad (de cero a catorce años, y de catorce a dieciocho años). Inicialmente, el comportamiento de gasto de las parejas casadas con un hijo no se examinó, como se había hecho en los tiempos de la Ley Federal sobre la Ayuda Social.

3. La valoración particular del estudio de patrones de renta y consumo de 2003 ha determinado algunos cambios en lo que se refiere al gasto que es relevante a fines del cálculo del importe ordinario del art. 2.2 del Decreto sobre el Importe Ordinario a partir del 1 de enero de 2007, pero no ha determinado un aumento del importe ordinario de base y de la prestación ordinaria para los individuos. Una nueva valoración particular, realizada sobre el comportamiento de gasto de las parejas casadas con un hijo, indujo al Parlamento a introducir un tercer grupo de edad para los menores que viven en el mismo núcleo familiar: desde los seis a los catorce años. A partir del 1 de julio de 2009, según el art. 74 del SGB II, reciben el setenta por ciento de la prestación ordinaria de una persona. Desde el 1 de agosto de 2009, según el art. 24.a SGB II, los niños en edad escolar reciben, además de esto, ulteriores prestaciones para la escuela equivalentes a cien euros por año escolar.

4. El 20 de octubre de 2009 se desarrolló en la Sección Primera del Tribunal Constitucional Federal (Bundesverfassungsgericht) la audiencia pública sobre el recurso presentado por el Tribunal Social del Land de Hessen, y sobre los dos recursos presentados por el Tribunal Social Federal, sobre la cuestión de si el montante de la prestación ordinaria para garantizar la subsistencia de adultos y menores hasta el cumplimiento de los catorce años, en el período que discurre del 1 de enero de 2005 al 30 de junio de 2005, a los que se refieren el art. 20.1 y 20.3 y el art. 28.1, párrafo 3, n.1, inciso 1 del SGB II, es compatible con la Ley Fundamental. En el comunicado de prensa alemán relativo a la audiencia se contienen informaciones detalladas acerca de los actos originales sobre los cuales se basa la presentación de los recursos.

\section{Decisión del TCFA}

La Primera Sección del Tribunal Constitucional Federal decidió que las disposiciones del SGB II que se refieren a la prestación ordinaria para adultos y niños no satisface el requisito constitucional previsto por el art. 1 en relación con el art. 20.1, ambos de la Ley Fundamental, como requisito orientado a garantizar un mínimo vital digno. Las disposiciones siguen en vigor hasta que el Parlamento apruebe nuevas disposiciones, a lo que estaba obligado antes del 1 de enero de 2011.

La Sentencia también dispuso que el Parlamento proveyese, al aprobar las nuevas normas, a garantizar una necesidad de naturaleza extraordinaria, inderogable, periódica y no sólo una tantum, de los sujetos que tienen derecho a las prestaciones del art. 7 del Libro II del Código Social, una necesidad que 
no esté ya cubierta por las prestaciones del art. 20 y siguientes del Libro II del Código Social, sino que deba obligatoriamente ser satisfecha para garantizar un mínimo vital digno.

La Sentencia también estableció que mientras el Parlamento no adopte nuevas disposiciones, tal derecho podrá hacerse valer directamente, conforme a los fundamentos de la Sentencia de conformidad con el art. 1.1 en relación con el art. 20.1 LF, y los costes correspondientes correrán a cargo del Gobierno Federal.

La Sentencia se basa sustancialmente sobre las siguientes consideraciones.

1.a. El derecho fundamental a la garantía de un mínimo vital digno, que deriva del art. 1.1 en relación con el principio del Estado social del art. 20.1 LF, garantiza a toda persona necesitada las condiciones materiales indispensables para su existencia y una mínima participación en la vida social, cultural y política. Además, del derecho que deriva del art.1.1 LF, a la dignidad de cualquier persona, que tiene efecto absoluto, este derecho fundamental que deriva del citado art. 1.1 tiene (en relación con el art. 20.1 LF) un significado autónomo como derecho de garantía. Tal derecho no está sujeto a lo que dispone el Parlamento y debe ser respetado; sin embargo, se le debe dar una forma concreta y además debe ser periódicamente actualizado por el Parlamento. Éste último debe adecuar, periódicamente, las prestaciones que corresponden al grado de desarrollo del ordenamiento y las leyes civiles y a las condiciones de vida vigentes.

Por lo que se refiere a los tipos de necesidad y los medios necesarios para satisfacer tales necesidades, la entidad del derecho constitucional a las prestaciones no se puede derivar de la Constitución. Corresponde por tanto al Parlamento dar a tal derecho una forma concreta. El Parlamento goza de márgenes de discrecionalidad para hacerlo.

A fin de dar una forma concreta al derecho, el Parlamento debe valorar todos los gastos necesarios para el sustento, con base en un método de cómputo idóneo y transparente, según la necesidad efectiva -es decir, adecuada a la realidad.

b. Los márgenes de discrecionalidad del Parlamento para valorar el mínimo vital se corresponden con un cuidado control de las disposiciones de las leyes no constitucionales por parte del Tribunal Constitucional Federal. Como la Ley Fundamental de Bonn no admite que se cuantifique exactamente el derecho, el control sustancial se limita, por lo que se refiere al resultado, a controlar si las prestaciones son claramente insuficientes. El derecho fundamental a la garantía de un mínimo vital digno no puede ser cuantificado por el Tribunal. Éste, en cambio, puede controlar las bases y el método de valoración de las prestaciones para averiguar si hacen justicia al objetivo al que se orienta el derecho fundamental. Para garantizar un diseño de la entidad de las prestaciones previstas por la ley que se adecue al significado del derecho fundamental, y para garantizar el control de las prestaciones por parte de los 
tribunales, la valoración de las prestaciones debe ser justificable sobre la base de cifras fiables y métodos de cómputo plausibles.

El Tribunal Constitucional Federal examina, por tanto:

1. si el Parlamento ha asumido y descrito el objetivo de garantizar una existencia que esté en línea con la dignidad humana, de manera que respete los requisitos del art. 1.1 LF en relación con el 20.1 LF;

2. si ha elegido, en el ámbito de los propios márgenes de discrecionalidad, un método de cómputo sustancialmente idóneo para estimar el mínimo vital;

3. si ha apurado completa y correctamente los hechos necesarios; y, por último,

4. si se ha movido dentro de los límites de lo que es justificable en el ámbito del método elegido y de sus principios estructurales en cualquier fase del cómputo y con cifras plausibles. Para hacer posible tal cálculo por parte del Tribunal Constitucional, el Parlamento está obligado a hacer públicos los métodos y las fases del cómputo utilizado en el procedimiento legislativo. Cuanto el Parlamento no cumpla tal obligación de manera satisfactoria, la determinación del mínimo vital -simplemente a causa de tales carencias-, no podrá considerarse conforme al art. $1.1 \mathrm{LF}$.

2. Las prestaciones ordinarias de 345, 311 y 307 euros no pueden considerarse netamente insuficientes para garantizar un mínimo vital digno. Por lo que se refiere al importe de la prestación ordinaria de 345 euros, no se llega a decir si está claramente por debajo del mínimo vital, ya que es suficiente, cuanto menos, para garantizar la faceta física del mínimo vital, y porque la discrecionalidad del Parlamento es particularmente amplia en lo que se refiere al perfil social del mínimo vital. Esto es válido igualmente para el importe de 311 euros fijado para el compañero adulto que vive en el mismo núcleo familiar. Al Parlamento se le permite aventurar la hipótesis de que vivir en un mismo núcleo familiar supone una reducción de los gastos y que, por tanto, dos personas que conviven tienen una necesidad financiera mínima inferior al doble de la necesidad de una persona que vive sola. No es además posible establecer que el importe de 207 euros, que se asigna indistintamente a todos los niños menores de catorce años, sea evidentemente insuficiente para garantizar un mínimo vital digno. En particular, no resulta evidente que tal importe no sea suficiente para cubrir el mínimo vital físico, sobre todo, la necesidad de alimentar a niños en edad comprendida entre siete y catorce años.

3 . El modelo estadístico que se aplica a la determinación de los importes ordinarios de acuerdo con la Ley de Ayuda Social, y que -según la voluntad del Parlamento- es también la base para la determinación de la prestación ordinaria es un método susceptible de ser compartido -y, por tanto, constitucionalmente admisible- para determinar de manera realista el mínimo vital para un individuo. Por otra parte, se basa en datos empíricos idóneos. El estudio de 
patrones de renta y consumo refleja el comportamiento de gasto de la población de manera estadísticamente fiable. La opción del treinta por ciento más bajo de los núcleos unifamiliares clasificados con base a la renta neta, tras haber excluido a los beneficiarios de la prestación de ayuda social como grupo de referencia para determinar la prestación ordinaria para un individuo es constitucional. El Parlamento podría también partir de la hipótesis de que el grupo de referencia sobre el que se basaba la valoración del estudio de patrones de renta y consumo de 1998 se colocaba por encima del umbral de la ayuda social de manera estadísticamente fiable. Es también constitucional que el gasto de la franja inferior, valorado en las diferentes secciones del estudio de patrones de renta y consumo, no sea considerado plenamente, sino que se considere, por el contrario, solamente un cierto porcentaje como gasto que es relevante a los fines de las prestaciones ordinarias para estimar la prestación ordinaria misma. Sin embargo, el Parlamento debe decidir qué gasto forma parte del mínimo vital de manera idónea y susceptible de ser compartida. La reducción de las partidas de gasto, en las diferentes secciones del estudio de patrones sobre renta y consumo, requiere una base empírica, para que puedan ser justificadas. El Parlamento puede considerar irrelevantes gastos que le consten que son efectivos, sólo cuando esté seguro de que pueden ser cubiertos de otra manera y no sean necesarios para garantizar el mínimo vital. Para establecer la cantidad de las reducciones no se excluyen las estimaciones, aun cuando sean llevadas a cabo sobre una base empírica muy sólida, no constituyendo las estimaciones realizadas arbitrariamente una modalidad realista de valoración del importe.

4. La prestación ordinaria de 345 euros no ha sido estimada de manera conforme a la Constitución, porque los principios estructurales del modelo estadístico se han abandonado sin una justificación efectiva.

a) El gasto fijado en el art. 2.2 del Decreto sobre el Importe Ordinario de 2005, que es relevante a efectos del importe ordinario y, por tanto, también a efectos de la prestación ordinaria, no se basan en una estimación practicable del estudio de patrones de renta y consumo de 1998. Porque, por lo que se refiere a algunas partidas de gasto, las reducciones porcentuales para los bienes y servicios que no son relevantes a los fines de la prestación ordinaria (es decir, pieles, vestidos a medida y alas delta) han sido efectuados sin que sea seguro si el grupo de referencia (la franja inferior) ha tenido efectivamente tales gastos.

b) Prescindiendo de esto, la proyección de las sumas valoradas para 1998 hasta el 2005 sobre la base de la evolución del actual valor de las pensiones representa una modificación inadecuada. Mientras el método de valoración estadístico se concentra en la renta neta, en el comportamiento de los consumidores y en el coste de la vida, la proyección según el valor actual de las pensiones se basa en la evolución de las retribuciones brutas, en las contribuciones al seguro general de pensiones y en un factor demográfico. Sin embargo, estos factores no presentan ninguna relación con el mínimo vital. 
5. La fijación de la prestación ordinaria en un importe de 311 euros para las personas que viven juntas en un mismo núcleo familiar no satisface los requisitos constitucionales, porque las carencias que han aparecido en lo que se refiere a la determinación de la prestación ordinaria para los individuos, aparecen también para la prestación ordinaria para las parejas, dado que su prestación ordinaria se valora sobre la base de los individuos. Sin embargo, la hipótesis de que un importe equivalente al $180 \%$ de lo necesario para un solo individuo es suficiente para garantizar el mínimo vital de dos personas que conviven, se funda, en efecto, en una base empírica suficiente.

6. La prestación social de 207 euros para los menores de catorce años no satisface los requisitos constitucionales porque deriva de la prestación ordinaria de 345 euros, respecto de la cual ya se han realizado objeciones. Además, la fijación del importe no se basa en un método de determinación del mínimo vital para un menor de catorce años que sea susceptible de ser compartido. El Parlamento no ha establecido en absoluto la necesidad específica de un niño; necesidad, que a diferencia de la de un adulto, debe considerar las fases de desarrollo de un niño y un desarrollo adecuado de su personalidad. La reducción del $40 \%$ sobre la prestación ordinaria de un individuo se ha fijado libremente sin ningún fundamento empírico o metodológico. En particular, los gastos necesarios para los libros de texto, los cuadernos, las calculadoras, etc., que forman parte de las necesidades de un niño, se excluyen del cómputo. Sin cubrir estos gastos, los niños que tienen necesidad de ayuda, corren el riesgo de verse sin ninguna oportunidad vital. Además, hace falta un cálculo diferenciado de las necesidades de los niños más pequeños y más mayores.

7. Estas violaciones de la Constitución no han sido eliminadas ni por la valoración por patrones de renta y consumo de 2003 ni por la nueva fijación del gasto relevante a efectos de la prestación ordinaria a partir del 1 de enero de 2007, ni tampoco por los arts. 74 y 24.a del SGB II que entró en vigor a mediados de 2009.

a) La reforma del Decreto sobre la Prestación Ordinaria, que entró en vigor el 1 de enero de 2007, no eliminó los defectos esenciales, como por ejemplo el hecho de que el gasto registrado en la sección 10 (educación) no se tomara en consideración, o la proyección de los importes valorados para 2003 con base en la evolución del valor actual de las pensiones.

b) La prestación social correspondiente a los niños de entre siete y catorce años, equivalente al $70 \%$ de la prestación ordinaria de un individuo, que fue introducida por el art. 74 SGB II, no respeta los requisitos constitucionales: en primer lugar, porque deriva de la prestación ordinaria, que no ha sido fijada correctamente. Es verdad que al introducir un tercer grupo de edad y al utilizar la determinación del importe que se basa en el art. 64 SGB II, el Parlamento probablemente se habrá acercado más a una determinación realista de las prestaciones necesarias para los niños en edad escolar. Sin embargo, a pesar de eso, no ha satisfecho los requisitos previstos para la determinación 
de la necesidad específica de un niño, porque la disposición legal sigue basándose en el gasto de un individuo adulto.

c) La disposición del art. 24.a SGB II, que prevé una prestación no periódica de cien euros, no entra en la necesidad prevista por el SGB II desde un punto de vista metodológico. Además, el Parlamento no determinó empíricamente la necesidad escolar de un niño cuando aprobó el art. 24.a SGB II. Naturalmente, el importe de cien euros por año escolar se basaba en una estimación libre.

8. Además, es incompatible con el art. 1.1 en relación con el art. 20.1, ambos de la LF, que el Libro Segundo del Código Social no contenga una disposición que prevea un derecho a las prestaciones para garantizar una necesidad de naturaleza extraordinaria, periódica y no sólo una tantum, y que es innegablemente necesario para garantizar un mínimo vital digno. Tal derecho es necesario para aquellas necesidades que no estén cubiertas por los artículos 20 y ss. SGB II, porque la recogida de datos por patrones de renta y consumo, que es la base de la prestación ordinaria, refleja sólo la necesidad media en condiciones de necesidad normal, pero no una necesidad de naturaleza extraordinaria que se derive de condiciones de necesidad atípicas que excedan de la necesidad ordinaria.

Es admisible conceder una prestación ordinaria con un importe fijo. Si el modelo estadístico se usa respetando requisitos constitucionales y, en particular, si la suma total se fija de modo que sea posible compensar las diferentes partidas de gasto, normalmente la persona que tiene necesidad de ayuda estará en condiciones de organizar su propio comportamiento de gasto de manera que pueda salir adelante con el importe fijado; en caso de necesidad de naturaleza extraordinaria, la persona deberá sobre todo recurrir al potencial de ahorro contenido en la prestación ordinaria. Las estadísticas no reflejan de manera convincente una necesidad que se presente en casos extraordinarios porque, habida cuenta de la manera en que se ha concebido, una prestación ordinaria global puede cubrir solamente una necesidad media. El art. 1.1 en relación con el 20.1, ambos LF, prevé la obligación de cubrir también tal necesidad de naturaleza extraordinaria, inevitable y periódica, no sólo una tantum, si ello es necesario en determinados casos para garantizar un mínimo vital digno. Tal necesidad no está todavía cubierta sin excepciones en el SGB II. Dada esta laguna en la cobertura del mínimo vital para el sustento, el Parlamento debe prever disposiciones para los casos de dificultad, en forma de derecho a las prestaciones de ayuda para satisfacer esta necesidad de naturaleza extraordinaria para los que tengan derecho a las prestaciones del artículo 7 SGB II. Sin embargo, este derecho se tiene solamente si la necesidad es tan notable que el importe total de las prestaciones concedidas a la persona que tiene necesidad de ayuda -incluidas las prestaciones que correspondan a terceros y teniendo en cuenta las posibilidades de ahorro de la persona que tiene necesidad de ayuda- ya no garantiza el mínimo vital digno. Dados los estrictos y rigurosos requisitos establecidos para este elemento constitutivo, tal derecho probablemente se considerará sólo en casos infrecuentes. 
9. Las normas inconstitucionales siguen siendo aplicables hasta que el Parlamento apruebe nuevas disposiciones, lo que estaba obligado a hacer en un plazo que concluía el 31 de diciembre de 2010. Dados los márgenes de acción del Parlamento, no le corresponde al Tribunal Constitucional Federal la fijación de un determinado importe de las prestaciones con base en las propias estimaciones y valoraciones. Como quiera que no es posible establecer que los importes de la prestación ordinaria fijados por ley sean claramente insuficientes, el Parlamento no está directamente obligado por la Constitución a fijar prestaciones más elevadas, pero debe, con base en las indicaciones recibidas, desarrollar un procedimiento para determinar las prestaciones necesarias para garantizar un mínimo vital digno, que sea realista y tenga en cuenta la necesidad efectiva, y debe plasmar el resultado en una ley como derecho a las prestaciones.

El art. 1.1 LF, en relación con el art. 20 LF, no obliga al Parlamento a fijar prestaciones con efecto retroactivo; sin embargo si el Parlamento no cumpliera la obligación de aprobar una nueva normativa antes del 1 de enero de 2011, una eventual ley contraria a tal obligación aprobada posteriormente deberá ser declarada aplicable desde el 1 de enero de 2011. Además, el Parlamento tiene la obligación de crear no más tarde del 31 de diciembre de 2010, una normativa en el ámbito del SGB II, que garantice que se satisface una necesidad de naturaleza extraordinaria inevitable, periódica, y no sólo una tantum.

Las personas que tienen derecho a las prestaciones del art. 7 SGB II que tengan tal necesidad, deben en todo caso percibir las prestaciones necesarias tanto pecuniarias como en especie, incluso antes de la aprobación de la nueva normativa. Para evitar el peligro de una violación del conjunto de los arts. 1.1 y 20.1 LF, en el periodo de transición hasta la introducción de nuevas disposiciones, la laguna inconstitucional correspondiente al periodo de la fecha de la aprobación de la Sentencia en adelante debe ser colmada mediante un auto en tal sentido del Tribunal Constitucional Federal.

\section{Bibliografía}

ARAGÓn ReYes, M., "Constitución española: economía de mercado y Estado social”, El principio de igualdad (ed. García San Miguel, Luis), Dykinson S.L., Madrid, 2000.

CASCAjo CAStro, J. L., La tutela constitucional de los derechos sociales, Centro de Estudios Constitucionales, Madrid, 1988.

Cobreros Mendazona, E., "Reflexión general sobre la eficacia normativa de los principios constitucionales rectores de la política social y económica del Estado", Revista Vasca de Administración Pública, 19, 1987, pp. 27 y ss.

FernándeZ-Miranda CAMPOAmor, A., "El Estado Social", Revista Española de Derecho Constitucional, año 23, $\mathrm{n}^{\circ}$ 69, septiembre-diciembre 2003, pp.139-180. 
FISAHM, ANDREAS y MöLler, M., "Lo Stato sociale in Germania: il Tribunale Constituzionale Federale "parla" alla politica note sulla sentenza del Tribunale Constituzionale del 9 de febbraio 2010", en Rivista Giuridica del Lavoro e della previdenza sociale, anno LXI, 2010, № 3, páginas 395 y SS.

Garrorena Morales, Á., El Estado español como Estado social y democrático de Derecho, Universidad de Murcia, 1980.

JiMÉNEZ CAMPO, J., "Comentario al art. 53 CE”, en Oscar Alzaga Villaamil, Comentarios a la Constitución Española de 1978, EDERSA, Madrid, 1996, pp. 439 y ss.

JiMÉnEZ CAMPO, J., Derechos fundamentales, Derechos y garantías, Editorial Trotta, Madrid, 1999.

PÉREz Royo, J., La doctrina del Estado social en la jurisprudencia del Tribunal Constitucional, en REDC, n. 10, Madrid, 1984.

Pomed SÁncheZ, L., "El derecho al medio ambiente", en M. Contreras, L. Pomed, R. Salanova (coord.), Nuevos escenarios y nuevos colectivos de los derechos humanos, Gobierno de Aragón, Departamento de Presidencia y Relaciones Institucionales, Zaragoza, 1998.

PRIETO SANCHís, L., "Los derechos sociales y el principio de igualdad sustancial", Revista del Centro de Estudios Constitucionales, 22, 1995, pp. 9 y ss.

Rodríguez de Santiago, José María, “Art. 53.3. La forma de vincular de los preceptos del Capítulo Tercero del Título Primero de la Constitución Española”, en CASAS BAAMONDE, M. E., Y RodríGUEZ-PiÑERO Y BRAVO-FERRER, M., Comentarios a la Constitución Española, Fundación Wolters Kluwer, Madrid, 2008, pp. 1187 y ss.

Serrano-SúÑEr Hoyos, G., y TenORIO SÁnchez, P. J., "Salvaguarda de los derechos fundamentales frente al ruido", Revista de Derecho Político, n ${ }^{\circ}$ 62, 2005, UNED, Madrid, pp. 95-146.

Torres del Moral, A., "Constitucionalización del Estado social", Revista Europea de Derechos Humanos, n' 13, monográfico sobre "La actualidad de los derechos sociales en España y en Europa", coordinado por L. Jimena Quesada, Instituto de Derecho Público y Fundación Profesor Manuel Broseta, Madrid, 2009.

Torres del Moral, A., Principios de Derecho constitucional español. Tomo I: Sistema de fuentes. Sistema de los derechos, Servicio de Publicaciones de la Facultad de Derecho de la Universidad Complutense de Madrid, $6{ }^{\text {a }}$ edición, Madrid, 2010.

TORRES DEL Moral, A., Realización del Estado social y constitución económica, ejemplar mecanografiado. 